
anc

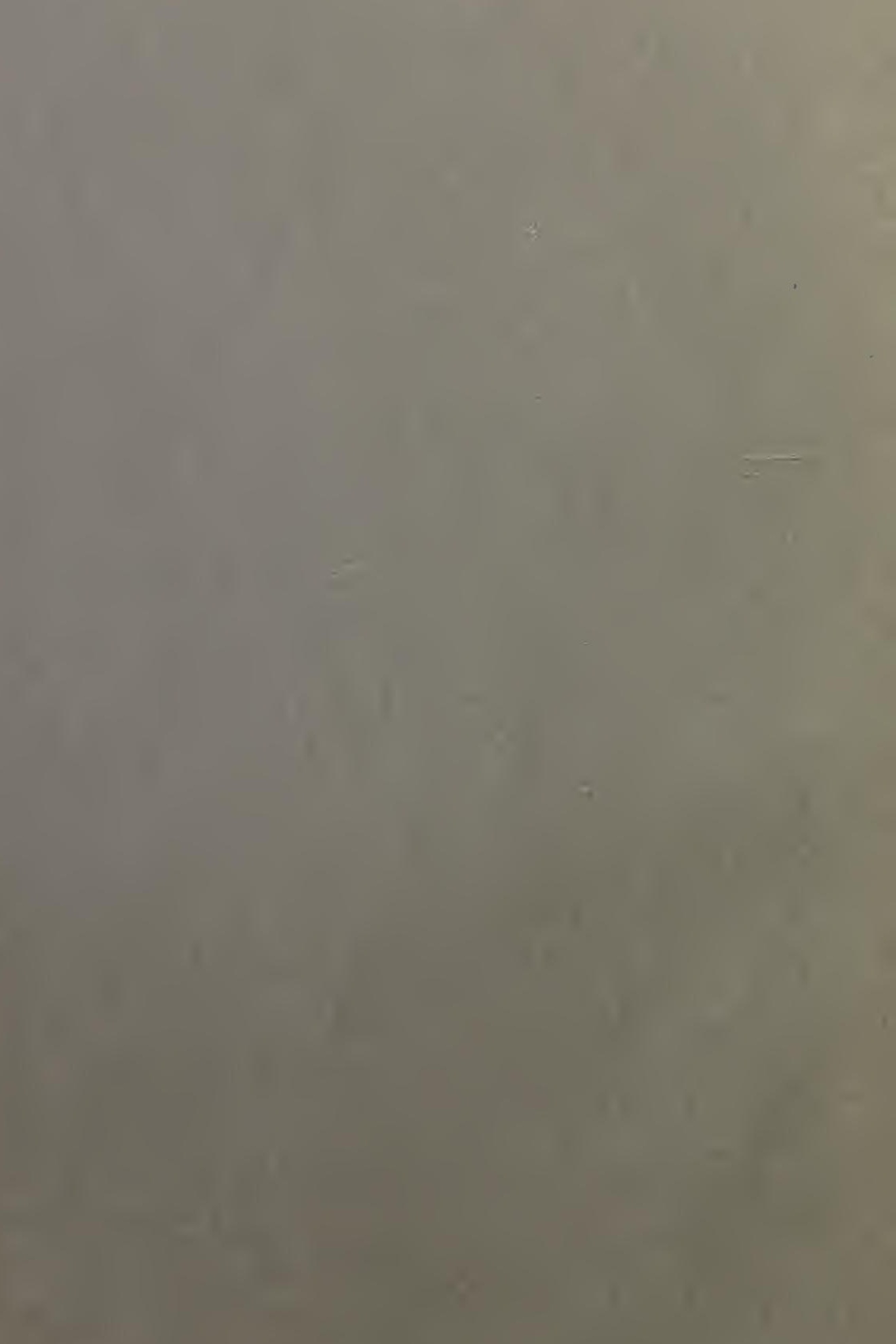




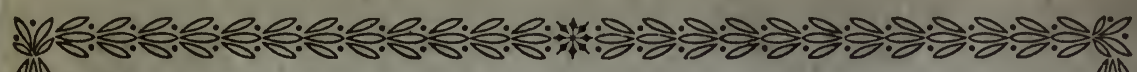
on

The ....

\section{Published by authority of the Society.}
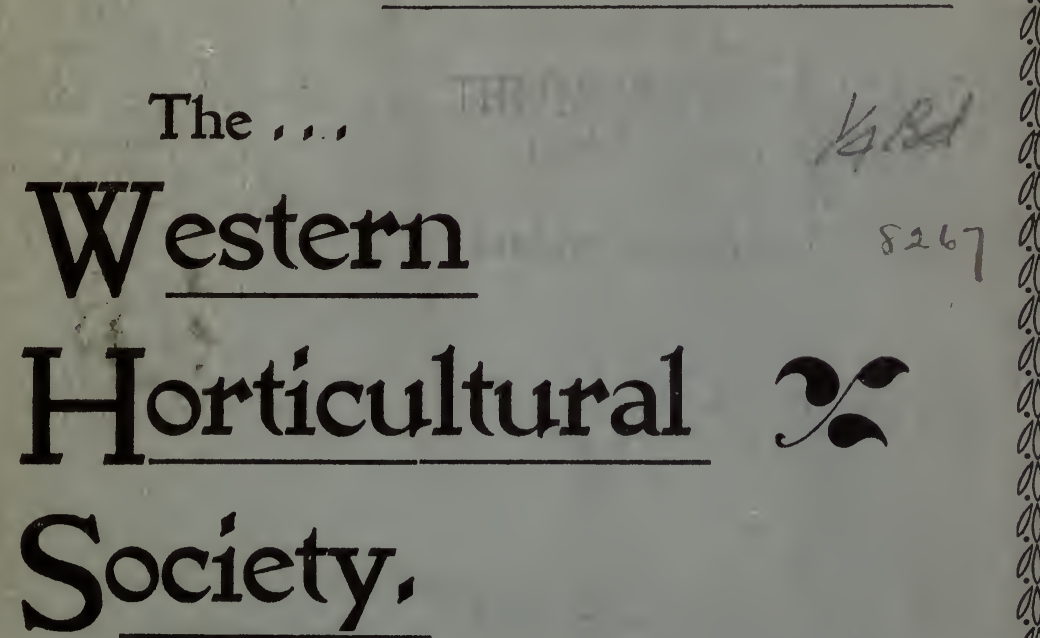

\section{Che Constitution,}

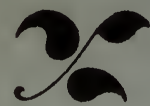

Che Annual Report,

\section{Che Papers Read}

During the years

Feb'y, 1896, to Feb'y, 1898.
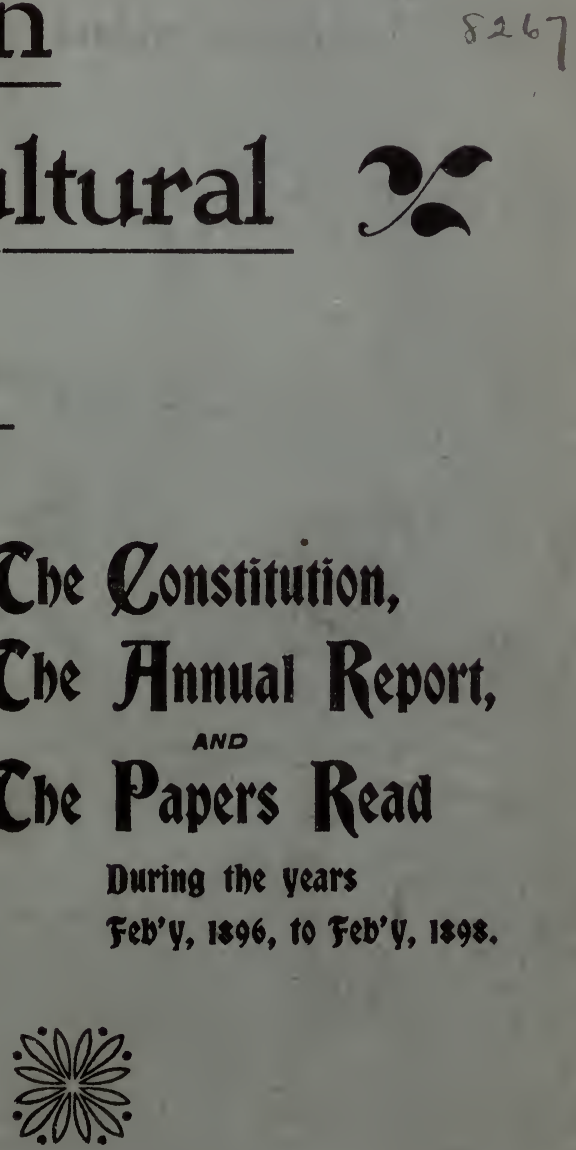

McIntyre Bros,, Publishers, Winnipeg, 1898. 


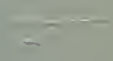

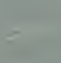


THE

7Clestern Forticultural Society.

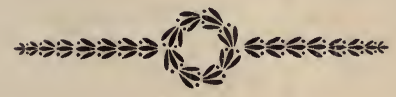

The Constitution, the Annual Report, and the Papers Read during the years

February, 1896, to February, 1898.

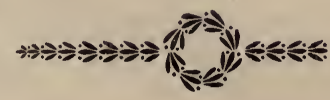

PUBLISHED BY AUTHORITY OF THE SOCIETY.

$$
\text { 潾潾 }
$$

tUinnipeg :

MCINTYRE BROS.,

Publishers.

1898. 


\section{Table of Contents,}

$\circ \circ \circ$

Page.

Constitution $\ldots \ldots \ldots \ldots \ldots \ldots \ldots \ldots \ldots \ldots \ldots \ldots \ldots \ldots, 5$

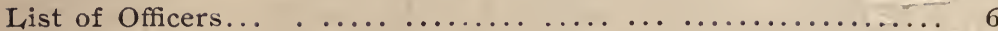

List of Members............................... 7

House Plants $-R$. Alston......................... 10

Ornamental Shrubs and Hardy Perennial Plants-W. G. Scott... 15

Practical Tree Planting-D. D. England................ 22

Small Fruits for Manitoba-T. Frankland............... 27

Winter Flowering Bulbs-R. Alston ................... 31

Growing Flowers in the Home-Mrs. J. McLeod Holiday......... 37

Prairie Flowers Suitable for Cultivation in Gardens-

Rev. W. A. Burman... 41

Annual Report of the Society ....................... 50

Organized Horticulture in the North West-A. W. Latham...... 51

Doubtful Fruits - A. P. Stevenson ..................... 60

Trees and Windbreaks-Angus Mackay ................. 68

Winter Protection of Plants-Rev. A. B. Baird ............... 73

The Importation of Fruit and Nursery Stock-R. R. Scott...... 80

Protection of Birds-Rev. W. A. Burman ................. 84

Forestry -E. F. Stephenson........................ 88

Bee Keeping-S. A. Bedford.......................... 95

Strawberries-H. C. Whellams ....................... 103

The Dahlia-A. F. Angus ......................... 111 


\section{Constitution,}

1. The name of the Society shall be the Western Horticultural Society.

2. Its object sha11 be the advancement of the interests of Horticulture, especially in the region between Lake Superior and the Rocky Mountains, by collecting, arranging and disseminating information on the subject, or by such other means as may be agreed upon.

3. Its membership shall include all who pay an annual fee of $\$ 1$, or a life membership fee of $\$ 10$, in one or two payments.

4. The Society may also elect honorary members for a period of five years or for life.

5. The Officers shall include an Honorary President, a President, six Vice-Presidents, a Secretary, a Treasurer, and three Councillors.

6. Five of the Vice-Presidents shall be chosen from districts outside of Winnipeg.

7. The Officers resident in Winnipeg sha11 constitute an Executive Committee.

8. The meetings of the Society shall be held at such times as may be agreed upon by the Executive Committee.

9. The officers sha11 be elected at the annual meeting, which slia11 be held in the month of February in each year.

10. Alterations of the Constitution can only be adopted by a twothirds vote, and only at an annual meeting, or at a meeting, in view of which, notice of the proposed amendment has been given.

\section{B Y, L A W S.}

1. Three meinbers of the Executive Council shall form a quorum.

2. The Secretary shall be responsible for giving due notice of each meeting to the members.

3. At any regular meeting of the Society the order of business sha11 be that proposed by the Executive and announced by the Chairman. In the absence of such prepared order of business the following sha11 be observed:
(1) Calling to order.
(2) Reading and Confirming of Minutes.
(3) Reading and Referring Letters, Accounts, etc.
(4) Reports of Committees.
(5) Inquiries and Notices of Motion.
(6) Nomination and Election of Members
(7) Unfinished and Miscellaneous Business.
(8) Adjournment. 


\title{
Officers of the
}

\section{Western Horticultural Society, 1898.}

\author{
PRESIDENT: \\ REV. PROFESSOR BAIRD.
}

VICE-PRESIDENTS:

S. A. BEDFORD, Brandon, Man.

R. S. Thornton, M.D., Deloraine, Man.

E. A. Struthers, Russell, Man. A. P. Stevenson, Nelson, Man.

Angus Mackay, Indian Head, Assa.

R. Alston, Winnipeg, Man.

SECRETAFY:

A. F. ANGus, Winnipeg.

\section{TREASURER :}

W. G. SCOTT.

COUNCILLORS:

REV. Dr. Bryce. G. H. GREIG. H. C. WhELLAMS. 


\section{LIST OF MEMBERS.}

\section{7.}

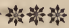

Alston, Richard................Winnipeg.

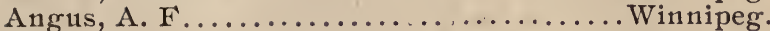
Baird, Rev. A. B .................Winnipeg.

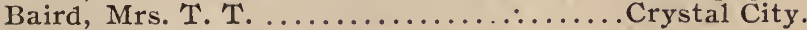

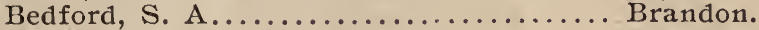

Benson, Dr. E...................Winnipeg.

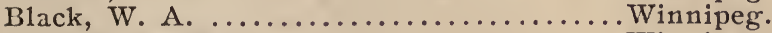

Blackwood, Wm..................Winnipeg.

Blakely, Dr. E. A..................Winnipeg.

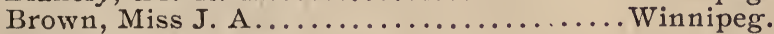

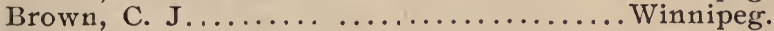

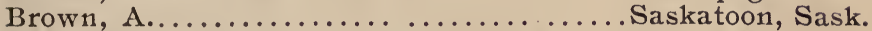

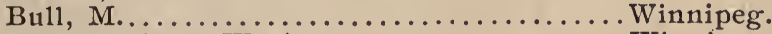

Burman, Rev. W. A. ...............Winnipeg.

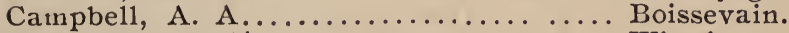

Carruthers, G. F................. Winnipeg.

Clark, Dr. C. W. ................... Winnipeg.

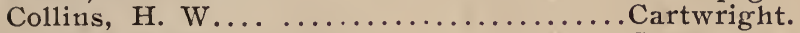

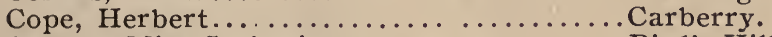

Cutten, Miss Catharine .................... Hird's Hill.

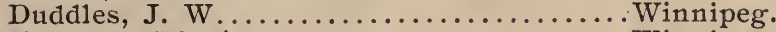

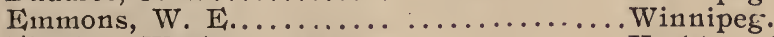

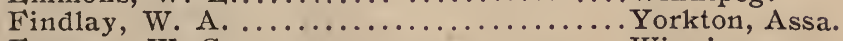

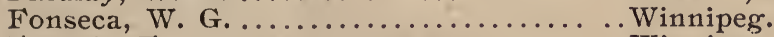

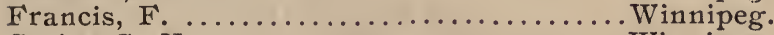

Greig, G. H... ................ Winnipeg.

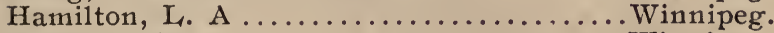

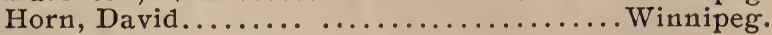

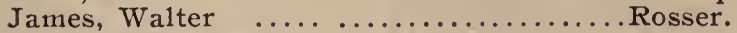

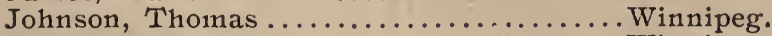

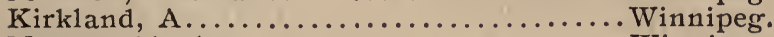

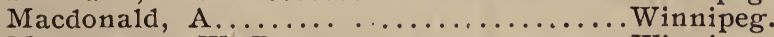

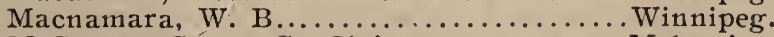

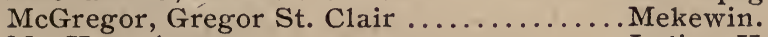

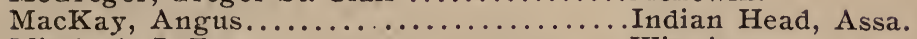

Mitchell, J. B...................Winnipeg.

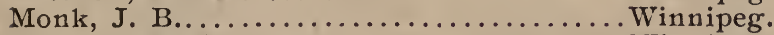

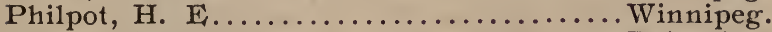

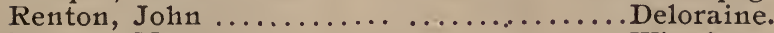

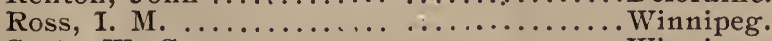

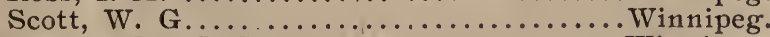

Skead, Mrs. J. S...................Winnipeg.

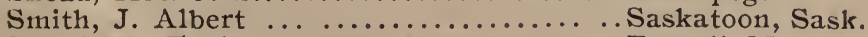

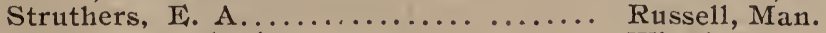

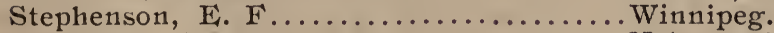

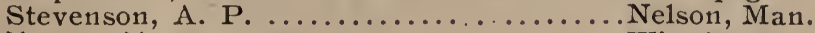

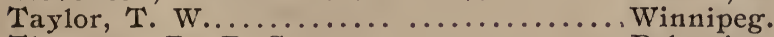

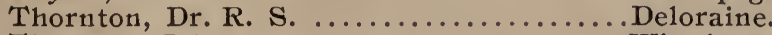

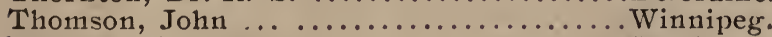

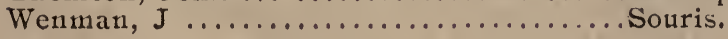



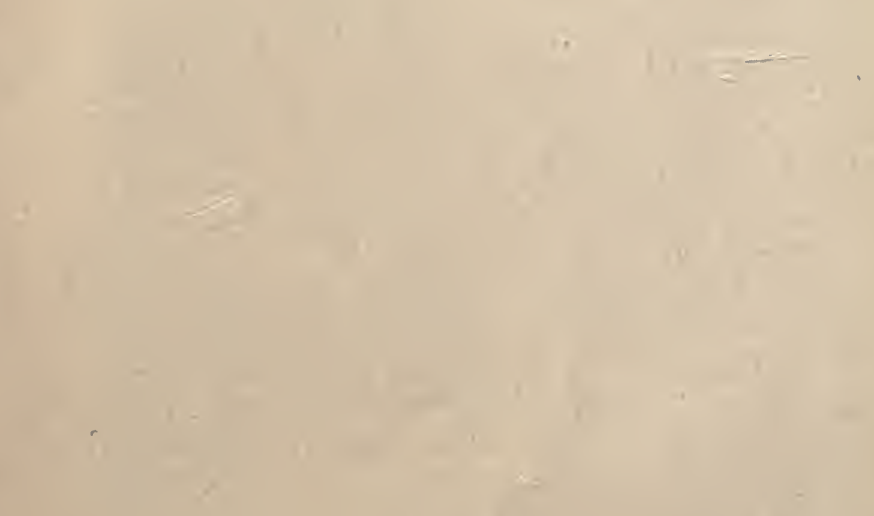

in

, 


\section{House Plants.}

\section{BY R. ALSTON.}

Feb. 20th, 1896.

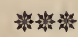

In response to our chairman and the Manitoba Horticultural Society to speak on such an important subject as how to grow house plants, how to water them, how to prevent insects, and how to transplant, I may say that it gives me great pleasure to do so this evening, and I will do so to the best of my ability, but I have had very short notice, and have very little time to devote to such work at this time of the year. This subject, to my mind, is a very important one, and $I$ think it needs handling by a more fluent and able speaker than myself, and I feel my inability to speak on the subject even to my own satisfaction, that is as I.think it ought to be explained. It is the many enquiries, and I might say complaints, about all kinds of plants, that have been made to me from time to time, that have suggested many of the points of which I am to speak to-night.

To grow plants in the house is not a very difficult thing to do, if the right methods are taken; success depends a great deal upon the care and attention given to them, that is the right attention which I will speak of later.

Some rooms are far more adapted for growing of plants than others, one with a southern aspect into which the sun shines the greater part of the day is the best, but it is quite possible to have plants do well in a room into which the sun never shines, that is, providing the right varieties are chosen, such as ferns, palms, begonias and many other foliage plants. Of course flowering plants will not do well without sunlight, that is they will not flower, but at the same time might grow just as freely as the foliage plants. The most essential thing next to the sunlight is the moisture without which no plant 
will grow. The high temperature which most of the dwelling houses are kept up to in this country, and the lack of moisture caused by the same, makes it very difficult to grow plants. We very often hear of injury to plants from gas and furnace heat; this really means that the vitality of the air has been exhausted by the methods of lighting and heating. In this cold climate, where so much heat is needed to keep the houses warm, we must have some means of supplying moisture if we want to succeed with plants in the house in the winter months. And I would advise all who wish to have plants succeed in the winter to have a very shallow tin or tank made the size of the window in which they wish to grow their plants. The tin to be about two inches deep, in which invert saucers and place the plants on them; keep water in the tin not quite the height of saucers. I have never seen this idea tried, but I have advised many to do so. This would counteract the dry atmosphere, and cause a moisture to rise among the plants, and thus aid them in their otherwise struggle for existence. This would apply to our winter months, but would be very beneficial even in summer. The rubber sprinkler would be another great help in growing plants, and could be used in connection with the tank to sprinkle the plants overhead once or twice a week in winter and oftener in the summer. As soon as the weather is mild enough to open the windows we should do so at once and let in the fresh air full of moisture, which is as welcome to the plants growing in the dry air as the stream is to the thirsty traveller.

Ventilation is another very important thing in plant growing, and ought to be given with great caution during the fall, winter and spring months. Lift the sash about an inch or two in the middle of the day, or open another window to avoid all draughts strong enough to stir the foliage in that part of the room where the plants are; never ventilate unless the temperature where the plants are is above fiftyfive degrees. Plants generally suffer more from the temperature being too high than if it is too low. No plants are likely to be grown in a house which would not thrive in tem- 
perature of sixty degrees, and at fifteen above freezing on the coldest night they will probably not be injured by the cold.

\section{How to Water Plants.}

There is one thing that should be remembered, and it is this, that the warmer the room is, the more water the plants will require, as they then have to depend absolutely on the moisture in the soil, and consequently absorb the moisture much quicker from the same, and must therefore be watered much oftener. The watering of plants is a very important thing, and very often it is not attended to as it ought to be done, and then in many cases it is attended to too well, a great many people having the idea that plants should be watered every day. In some cases they would stand it but in others they would not. How often should we water our plants? is a question that is asked me more than any other, and I invariably have a smile when I answer "when they need it." There is no such thing as having to water a plant every day, every two days or every three days. You might water a plant to-day and it might need it again to-morrow, or it might not need it for two days. Then you will naturally ask the question, How are we to know when to water our plants? This would depend upon the circumstances under which the plant is being grown. If it is over a tank containing water like the one previously mentioned, you would not have any trouble in finding out when the plant needs watering, as you could tell by tapping the pot, and if it has a clear bell-like sound it is dry and needs watering, but if it has a dull sound it does not require water. Avoid extremes in all cases, and do not let the plant be too dry or too wet, and above all do not let your.plants stand in water.

House plants ought to be kept free from dust, as the minute particles enter the pores of the leaves and thus prevent the healthy growth of the plants. They should be sponged over once a week with soapy water, or which is better, water containing a little fir tree oil. This will also improve the appearance of the plants and keep them free from insects of various kinds. 


\section{INSECTS.}

There are many kinds of these to which plants are subject, particularly in the dry atmosphere of the house. The Aphis or green fly is the most common, and every one will know it who has tried to grow plants in the house; these insects are easily killed with tobaoco smoke, if you have means of confining the smoke around the plants, but you might smoke until you were tired, if sou simply blew the smoke among the plants, as it goes away from the other side without having the beneficial effect. Any plant that can be washed easily can be kept.clean by washing it, but any person having a number of plants can keep them clean of green flies in the following manner: Take a tin trunk or any other kind of a trunk just as long as it is air tight, into which place tobacco stems from six to twelve inches deep, all you then need to do would be as soon as you see green flies on your plants to place them in the trunk over night (be sure and close the lid down tight), and in the morning your plants would be free from green flies. The trunk you must keep closed for this purpose, keeping the strength of the tobacco in the same, and it would always be ready whenever the insects are discovered on our plants. Thrip, or red spiders, are very small insects, and are caused by the atmosphere being too dry. Rose trees and fuchsias are the worst plants for these to get on as they generally lose all or most of their leaves before the insects are discovered, you will see the leaves turn a little yellow or a lighter shade than it is natural for them to be, and the only remedy for these is to keep the plants sprinkled as often as possible on the under side of the leaves.

Mealy bug is another insect which looks like a small piece of cotton on the plant, and is very easily washed off with either a sponge or a small brush with a mixture of fir tree oil and water.

Scale is an insect which I think is the worst of them all, as it is so difficult to wash off, and it needs the help of a small tooth or nail brush to dislodge it. In washing all 
plants for either insects or dust I would advise you to use a little fir tree oil in the water, as this will put a glossy appearance on your plants, and also prevent insects from coming on the same.

\section{How to Transplant.}

The first and most important thing is to have good soil to transplant in. The following is a good mixture:. Onehalf old sod, one-quarter leaf mould, and the other quarter made up of well decayed manure and sand. This mixture will do for almost any kind of plants, and if your plants do not thrive in this soil you will know that the fault is not due to the soil. Of course there are some very fine rooted plants which would do better if a good portion of peat be added to this soil, but it is not absolutely necessary, (such as Azaleas, Ferns), etc. Potting soil should never be used too wet or too dry. By taking the soil in the hand and squeezing it you can tell whether it is too wet or not. If it is not too wet it will crumble and fall, but if it is too wet it will stick together like a ball of clay. If the soil is dust dry sprinkle it an hour before using.

The next important thing is the way in which to repot a plant. I have had plants sent to me that have been potted in the most ridiculous manner. Sometimes they have been taken from the old pots and placed into a new one and the new soil placed loosely around it. The people seem to be afraid of hurting the plant by making the new soil firm in the new pot. As the new. earth being so loose would hold three times the amount of water that it would if made firm, and this over supply of water would turn the soil sour before the plant is rooted sufficiently to absorb the same, you would then wonder what had caused it to die. When you pot plants make the soil firm in every case. If you are potting small plants make the soil as firm as possible with the fingers, but if you are potting a plant into a larger pot it would be better for to use a flat piece of wood that will go between the old earth and the new pot, and thus be able to make the soil firm from the bottom to the top. Be sure and 
have the pot well drained with a few pieces of broken crocks, thus to insure good drainage. You will then not have to be so particular in watering as the over supply of water will drain away quickly.

Another important thing is the over-potting of plants, that is the potting of very small plants into very large pots. This ought never to be done, as it involves much more labor in finding out whether the plants need water or not. The safest plan is the repeated repotting of a plant from one pot to one a little larger. Plants potted in this way'will grow better and are easier managed and are better in every way. The right time to move a plant from a small pot to a larger one is shown by the roots beginning to mat around the outside of the ball that is next to the edge of the pot. It is almost amusing to see some amateurs start to repot plants. I have known them to take a knife and insert it all around the pot and thus scoop the plant out. Another favorite way is to break the pot with a hammer. I expect some of our lady friends do this who no doubt know well how to turn a pudding or jelly out of a mould, but who, I expect, have never given it a thought that the ball of earth enveloping the roots of a plant could be turned out of a pot in the same way. In most cases a slight tap of the pot on the edge of a table is quite sufficient to turn out the ball of earth. 


\title{
Ornamental Shrubs and Hardy Perennial Plants،
}

\author{
BY WM. G. SCOTT.
}

March 20th, 1896.

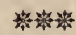

The subject that I have selected for this paper covers a very wide field, but in the limited time allowed we will confine ourselves to a few of the hardy varieties and such as are of easy culture, and requiring the least possible care, with the object of encouraging this much neglected branch of horticulture.

There will be more difficulty in growing with success the same varieties of shrubs and plants that grow to the east and south of us, and it is important that we fix upon a list that is recommended by those who have had experience here, so that there may be no waste of time, money or labor by the inexperienced, in trying such as are not adapted to the climate.

There is, perhaps, no city in the Dominion where planting has'been more neglected than in our own. The absence of trees on our streets and avenues, clumps of shrubbery on the margins of our lawns, and borders of hardy herbaceous plants is commented upon by visitors from abroad. True, our gardens are a blaze of glory while the annuals are in bloom from the middle of July until they are nipped by the early frosts, but outside of this there is nothing to attract attention except a few well kept lawns, which are too often disfigured with rockeries, the presence of which is a veritable eyesore upon what would otherwise be pleasant looking places.

Large and small gardens can be made very attractive from spring until late in August with a proper selection of shrubs and plants such as I shall now proceed to enumerate. 
LiLAcs. - Of hardy flowering shrubs I place the Lilac family first and foremost, as it is now more widely known than any other in cultivation, especially the old purple and white Lilacs of our grandmothers, to which I need not specially refer. Their cultivation in Canada dates almost from its first settlement, when our forefathers brought the bush with them from the old homes. Ever since it has been spreading from garden to garden until it is familiar to everybody. It will ever remain the most popular shrub on account of hardiness, ease of propagation and culture, and its exquisite perfume. Certainly nothing can exceed in beauty a good bed of lilacs in blooming time, and the foliage is always handsome. The only fault that can be found with it is its tendency to sprout from the roots. I would invite special attention to some of the improved but less commonly known varieties which deserve to be more widely cultivated. Of these varieties that have proceeded from the common types the following may be specially mentioned :

S. Caerala Superba.-The flowers of this variety are light purple in bud, but when fully open a clear blue.

Albert the Good.-Flowers of reddish purple, and is considered the best of its color.

Colmar's.-Large pale blue flowers, remarkably fine, glossy foliage.

Giant.-Unusually vigorous, with large leaves and flowers, the latter of a blue color.

Prince of Wales.-Flowers purplish lilac, panicles medium to large.

President Grevy.-A beautiful blue, individual flowers very double and very large. One of the finest lilacs.

The catalogues of Nurserymen contain scores of others, not one of which will be found unworthy of culture.

In cultivating this fine shrub it is well to arrange the plants in masses on the lawn or near the boundaries of the grounds. The larger the clumps the more delight they will afford. 
UPRIGHT HONEYSUCKLE. - Of the shrubs that withstand our severe winters the Honeysuckle (Lonicera) undoubtedly ranks next to the lilacs. They are strong growing shrubs of good habit, foliage a pretty shade of green, which gives it a pleasing appearance even when not, in bloom. The flowers appear early, are white and pink, sweet and abundant. It makes an admirable hedge or sçreen. The following are the best varieties of this shrub :

Tartarian.- Pink flowers, which contrast beautifully with the foliage.

White Tartarian.-Forms a high bush with creamy white flowers.

Pink Flowering.-Produces bright red flowers striped with white.

Grandiflora Alba.- U Uright habit, with very large white flowers.

BARBERRY.-This shrub occupies a prominent place among ornamentals. There are only two varieties that withstand our winters, and the terminal buds of these should be pinched about the middle of August. The fruit is very acid, and is largely used in the manufacture of jellies in the New England States, The common is, perhaps, the best for fruit. The purple variety is as hardy as the common, and when in bloom early in the season, or loaded with scarlet berries later is an object of great beauty. The plants are easily raised from seeds and from layers or suckers.

Flowering CUrRant.--This is one of the earliest flowering shrubs, and bears a profusion of blooms. It attains a height of four or five feet, is extremely hardy and should be more generally grown. The following two varieties are especially worthy of cultivation :

The Yellow Flowering.-Produces shining leaves and yellow flowers.

Gordon's Currant.-Flowers crimson and golden in pendant bunches.

One charm of these shrubs is the richly colored crimson hue which the foliage assumes in autumn. 
SPIREAS. - As far as my experience goes there are only two varieties of this beautiful shrub that are adapted for culture in this climate, viz : Sopulifolia and S. Van Houttee. Mr. Bedford, of the Brandon Experimental Farm, gives a list of six in addition to the foregoing that have proved a success at the Brandon Experimental Farm, the following are the varieties: Douglasi, Semperflorens, Superba, Billardi, Californica, Floribunda. S. Van Houttee is the best and most showy of all the spireas. It bloms early, grows to a height of five or six feet with a diameter nearly equal to its height. Flowers pure white in great clusters, foliage a lively green color.

\section{Virburnun, SNOWbali OR GUILDER ROSE.}

Common Snowball.-This popular old shrub is so perfectly hardy and so easily cultivated that it should be in every collection.

Virburnun Opulus. - High or Bush Cranberry.- This shrub is found wild in the woods on the Assiniboine and Red River, is both ornamental and useful. In flowering time it is a "blaze of splendor," and later in the year when laden with berries is very attractive.

This completes the list of flowering shrubs that I have experimented with. There are, no doubt, many others that will grow in this climate, and for the benefit of those who desire to make a larger and more varied collection I submit the following varieties that have been favorably reported upon by Mr. Bedford, viz : Southernwood, Russian ; Southerwood, European ; Cherry, ground or sand ; Siberian Dogwood; Caragana Pendula, (Weeping Caragana) ; Caragana Arborescens (Siberian Pea Tree); Golden Elder ; Snowberry; Cornus, native; Olive (Russian); Saskatoon, (native).

In selecting ornamental shrubs, only such should be taken as grow vigorously and bloom freely. The amateur will get little satisfaction, comparatively, out of a great variety, however interesting it may be to the botanist and 
collector. Our purpose should be the embellishment of home grounds, large and small, and we should choose such as are adapted for the purpose.

\section{HARDY PERENNIAL PLANTS.}

No grounds, however limited in extent, should be without some hard perennials, and it is difficult to understand why so few are cultivated. When once planted they are lasting, and do not need the care required to grow annuals. Perhaps the most satisfactory way to grow these " nurslings of nature" is in borders by themselves. I will refer briefly to a few species, supplementing these with a list which may be cultivated to advantage.

The P出ONy.-The Pæony is the noblest and showiest of the perennials and is very fragrant. I would strongly urge every person who owns a piece of ground to obtain a good collection of these plants, which George Ellwanger says "almost rivals the rose in brilliancy of color and perfection of bloom, and the rhododendron in stately growth."

The Chinese varieties are all hardy, and by having a dozen or more varieties-the more the better-one can have them in bloom from almost June 1st to July 15th. They do not bloom until the second year after planting, and scarcely need any attention. After they once kecome established they continue to increase in beauty year by year. The following list includes early, medium and late, and is perhaps as good a one as can be obtained :

P. Ambrose Vershaffelt-Purplish crimson, very fragrant.

P. Baron James Rothschild-Outside petals rose, centre salmon.

P. Delachi-Dark purplish crimson, shaded violet.

P. Eugene Verdier-Blush shaded with pink.

P. Globosa Grandiflora-White, large globular flowers.

P. Louis Van Houttee(Calot)-Bright purple cherry, large.

P. Madame Victor Verdier-Crimson rose, light violet, large.

P. Modeste-Deep rose. 
P. Papaveriflora-White, lightly tinged with yellow.

P. Papillionaceo-Outside petals rose, centre yellow.

P. Violacea-Deep purple violet.

P. Virgo Maria-Pure white.

PhLox.-These flowering plants include many varieties, and flower freely during July and August. When the plants are two years old they produce their finest trusses of bloom, and the third year they should be divided and transplanted. There are common varieties which may be obtained from any nursery. In addition to these a list might embrace the following distinct ones :

Abundance.-Bright purple, dwarf.

Adonis.-China rose, fine.

Amazone.-Pure white.

Avalanche.-Creamy white, dwarf.

Lothair.-Rich salmon color, one of the finest.

Madame Audry.-Crimson purple.

Obernon.-Coppery red.

Pantheon.-Pink or salmon rose.

Queen.-Pure white, fine.

William Robinson.-Pale salmon, flowers very large.

Eclatant.-Brownish red, purplish centre.

Epopee-Bright orange red, dwarf.

IRISES.-The German Iris has proved entirely hardy here, and are valuable plants for the garden. Their culture is very simple, only needing good soil and plenty of water during the blooming season. There are numerous varieties of as many colors and shades. I append a list which have proved exceptionally good here the first season:

I. Apollon.-Golden yellow.

I. Atropurpurea.-Purple.

I. Aurea.-Clear golden yellow.

I. Celeste.-Delicate light lavender blue.

I. Common Purple.-Purple, one of the best.

I. Eugene Sue.-Creamy white.

I. Flava,-Pale yellow. 
I. Hector.-Light bronze.

I. Florentina.-White, tinged with blue and yellow.

I. Ignititia.-White, suffused with purple.

I. Jacquesiana.-Deep maroon velvet.

I. Jordain.-Deep purple, shaded with rose.

LILIES. - The only varieties of Lilies that I have cultivated with success are the single and double Tiger Lilies. I have tried other varieties, but they have all failed. Mr. Bedford, I am informed, has met with fairly good success with other varieties, including the magnificent Japan Lily (Auratum). To produce good effects this should be planted in clumps. I have mentioned only a few of the many desirable hardy plants. To these might be added Larkspurs, Hemerocallis, Oriental Poppies, Trilliums, Cypripediums, Bleeding Heart, and many others, to describe which would require a large volume.

Roses.-A paper on shrubbery or plants would be incomplete without a reference to the Rose, but to do this flower justice woula require a separate paper. For out door culture in our climate Hybrid Perpetuals are the most desirable, and these need protection to bring them through our winters, in fact all the perennial plants I have mentioned should have a light covering of straw or other light material. The following varieties have been recommended by the Minnesota Horticultural Society for general culture in the State, and have been grown with success here:

General Jacqueminot.-Brilliant crimson, fragrant.

Fisher Holmes.-Dark crimson, a superb rose.

Alfred Colomb-Brilliant carmine crimson, one of the best.

Baroness Rothschild.-Light pink, without fragrance, a late bloomer.

Caroline de Diesbach.-Pale fresh color.

Annie de Diesbach-Carmine, a beautiful shade, fragrant.

Baron de Bonstetten.-Rich velvety maroon.

Paul Neyron.-Deep rose color, very desirable.

John Hopper.-Bright rose with crimson centre.

Madame Plantier (June Rose).-White, vigorous. 
When TO PLANT. - Having from the standpoint of an amateur advised "what to plant," I am fully convinced that all planting in this country should be done as early in the spring as possible. Trees and shrubs when transplanted in the fall are weakened by the loss of many fibrous roots and are less liable to withstand our severe winters.

How to Plant.-This subject, I understand, is to be dealt with by the superintendent of city parks at our next meeting, and no one is better able to deal with the subject than he.

WHERE TO BUy.-The tree agent with his "fancy pictures of impossible fruits," his cuts of magnolias, horse chesnuts and flowering plums will soon be intruding his presence on you for spring orders for plants at magnificent prices. My advice is to buy only from nurserymen and florists of good reputation, buy through catalogues and correspondence and let the smooth-talking agent severely alone.

\section{2 \\ Practical Tree Planting.}

BY D. D. ENGLAND.

April 20th, 1896.

䄅慗

On small ground or city lots trees not too high should be selected for planting. They should be bushy and clean looking. The look of a tall slender tree shows that it has been growing in the thick woods, and is, in consequence, drawn, and not fit for exposure. It will more or less relapse. The bushy tree has been more isolated and will stand exposure. The roots also will be bushy like the tree itself, and will have a large number of fine fibrous roots. These are what are needed, for the large roots are not of much use without the little ones. A bushy tree of this kind can be 
removed with little or no risk, but if a transplanted tree, such as is sold by nurseries, can be obtained, this will be by far the best.

It is always well to have variety, and if the trees are to be in line, this can be secured by having different shades, as the elm alternating with the basswood. If they are to be planted thick, arrange so that you can take the alternate ones out without irregularity. This will certainly be required in time, for you cannot get good shade trees if they are planted too thick. If the grounds are large it will be advisable to have clumps of trees. In this way they will grow better and look better, but care should be taken to mix the varieties in these clumps-little and big, standard and shrubby trees will grow well in this way that otherwise would not.

For hedges, the best thing is to plow or dig a furrow, and either put in small seedlings or seeds. In the case of willows cuttings will do, but they must be thick and they must be kept cut. The following are suitable for hedges :Caragana, or Siberian Pea, the Wild Rose, the Artemisia, the Willow, the Thorn, the Elm and the Maple.

\section{The Climate.}

We must not be disappointed if we are not successful in meeting the requirements of the climate at first, but by the help of fellow workers and of the members of our society, we can learn what will suit our conditions. Much blame in the matter of trees dying is alleged against our severe winter. But this is not the principal cause of failure amongst forest trees. I believe it is the hot dry weather preceding a sharp spell of frost, especially in the early fall; the frost comes and checks the trees, then when the sap has gone down we get two or three weeks of warm and dry weather. There is at this time no sap in the bark to keep it soft so it practically dries out. I have watched this minutely and find that the same thing happens in the spring. Sap rises from as far down as the tree is thawed out, and if the weather is very warm exhausts itself, then dries up, and as soon as the root 
thaws out the sap rises and bursts the dry bark. If we had a wet fall and no hot weather after the first frosts, followed by a cold wet spring, trees would do better. A good covering of dry litter will greatly benefit all kinds of trees, not only in winter but in summer too. Of course old established trees and hardy trees do not need such precautions, but all such as are imported and are tender should be protected from the South in the spring to prevent sun-scald. Then there is often a cold snap after the leaves are out followed by dry hot winds at the end of May or early in June. This is a critical time for trees, if their foliage is to amount to anything that season. We can partly make up for nature's deficiency in this respect by spraying an hour before sunset and an hour after sunrise, so long as the sun is not too hot. It is not sufficient to water the roots, as the foliage gets dry and will not draw from the roots. Spraying also, if done at the right time, would, in nine cases out of ten prevent the ravages of insects. Last summer, when the maples all round us were without leaf ours were fresh and green, by spraying with pure water without chemicals of any kind. Of course water without chemicals does not always answer, but in most cases it does, and at any rate prevention is better than cure.

\section{WhAT KIND OF TREES?}

I believe there are many kinds of trees that would do well here with which we have as yet made no experiments, but there are certainly a few kinds that will grow and flourish. The first and best is the elm, but if you want this to be a good shaped tree the knife must not be spared, because its inclination is to grow straight $u p$, and judicious pruning is the secret of making a well-shaped tree. The elm can be easily grown from seeds, but these must be gathered as soon as they are ripe and planted straight away. The second year they should be transplanted and the root pruned, because it is inclined, as all seedlings are, to make a tap root. If a good shaped tree is wanted it should be transplanted every three years till ten years old, or until it is permanently planted. 
Then there is the bass wood or linden, a very pretty tree. Its foliage is a light green and it has a fine large heartshaped leaf, and the tree, growing as it does, into a pyramid shape, makes a fine contrast to the elm and the dark-leaved oak. This tree requires the same treatment in planting as the elm. It is important that the soil should have good drainage, and a soft or more mixed loam to the roots. Basswood seedlings are more difficult to raise than those of the elm. The seed should be mixed in wet sand and allowed to remain out of doors all winter, then sown in the spring. This is done to soften the seeds before they will germinate. All hard seeds or shell seeds may be served in the same manner. For example, the mountain ash, the thorn and the oak. Cuttings of bass-wood may succeed very well, but this greatly depends on the weather, for cuttings like moisture and also a sandy soil.

The oak I have found a very stubborn tree. I have transplanted it and it has lived, but $I$ have had very little success with it. It will not stand pruning. If it is transplanted it must be put into the same kind of soil as it has been growing in before, and make the soil just as solid, for the oak likes to be firm. But since you must not prune, that means that you must get a large clump of earth at the roots.

Next come the native birches, which make a pretty contrast, owing to their various colors, for they are white, red and yellow. It is best to get the tree, though these can be had from the nursery, or grown from seeds, the same as the elm, but will not need so much pruning. The cut leaf weeping birch grows well and makes a fine ornamental tree for the lawn. This, of course, must be had from the nursery.

\section{The Time to Plant.}

As I have already stated, the spring is the best time for most trees. The reasons are, that if planted in the fall the hard wooded trees have not the same amount of sap in them that the maple, for instance, has, and consequently when the sun comes out in the spring it thaws out the tree but not the roots, and, as stated before, this exhausts the sap and dries 
out the tree. This is, I believe, why so many winter planted trees die. But for the Manitoba maple I think the fall is the best time to transplant; from the end of September to the end of October. The reason for this is, the fruiting season for this tree is the spring, and no tree should be moved while fruiting. This I have tried by removing sixty large trees. I began August 26th with one, September 5th two, September 10 th four, and from September 15 th to October 15th, fifty trees. All grew, but I found those moved from the 15th September to 15 th October came out the best. They should not be done later, as the tree bleeds badly in the spring, if cut after the frost is in it. No maples should be cut till the end of May. This tree needs more pruning than any other as it is of a soft, succulent nature.

\section{How TO PLANT.}

Suppose I want to get three feet of earth with a tree, the trunk of which is from four to six inches in diameter one foot above the surface of the ground. I would cut a circle three feet six inches from the tree-that means seven feet of rootsthen take a spade and start at the outside of the circle, the edge of the spade pointing to the trunk. all the time; then dig a trench twenty-one inches wide, without cutting off any roots, except at the outside of the circle. That will leave twenty-one inches from the trunk of the tree, or three feet six inches in diameter. Care must be taken not to cut the roots in digging, but to raise them and cover them with a wet sack so that the sun cannot get at them and dry them out. It is hopeless to get a tree of this size out of the ground with all the earth from which its roots draw support. In preparing the hole in which the tree is to be placed the earth should be taken out six or nine inches larger than the diameter of the roots and twelve inches deeper; the sides of the hole should be straight. If there is at hand any rough material, such as old sods, old lime or bricks, three or four inches of this will be valuable. Then cover with six or nine inches of sandy loam or good soil. Place the tree in the centre of the hole, then commence filling in around it, 
straightening out the roots in the meantime so that none of them is doubled up; let plenty of water run into the hole while it is being filled, and afterward make the soil firm, and stay the tree so the wind will not shake it. Next cut the tree well back, and I will guarantee that ninety per cent will grow.

Always see that the tree is planted so that there is no danger of the land being raised around it. The roots at the foot of the trunk slould always be a little higher than the surface. In many instances in raising land in the city the trees are allowed to remain and a box is put around the trunk. This is not satisfactory. The roots need air, and many a fine tree has died in the city, without warning, for want of breath. So when a tree is newly planted it should never have sod laid close up to the trunk but be left open till established, then sodded to within fifteen inches of the trunk, and, if possible, the soil round the tree should be cultivated.

\section{$x$ \\ Small Fruits for Manitoba,}

T. FRANKLAND.

May 21st, 1896.

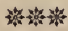

STRAWBERRIES.-This is the most important of the small fruits, and could selections of the largest natives be secured, their tendency to run to plants be checked, and the berry in some way made firmer for shipment, the quality, flavor and aroma being kept unimpaired, no better berry could be desired. The cultivated kinds have, however, captured our markets. These can easily be grown, and home grown fruit is undoubtedly superior to importations from Ontario or the United States. Where possible a northern slope or one shaded at the south is the ideal plot for a strawberry bed, as drying southerly winds often seriously affect the crop if 
planted on other exposures, and plants start latest on northerly slopes, and are not liable to be killed by late spring frosts. Good, rich, friable soil, deeply cultivated, is suitable, but strawberries should never be planted on sod land, un account of the liability of its being infested with cut worms or with the white grub which feeds upon the roots of the plants. A strawberry bed should be prepared in the fall before planting, and well rotted manure dug or plowed in, but not too deep. The plants may be set as early in the spring as the ground will work well, upon the fall prepared bed in rows $4 \mathrm{ft}$. wide, plants $1 \mathrm{ft}$. to $18 \mathrm{in}$. apart, and when well rooted the spaces between the rows dug or plowed. No fruit blossoms should be allowed to fruit the first year, as the plants will thereby be weakened. Clean culture is needed, and the runners confined to each side so as to make a matted row with a space between for mulching in dry weather and for convenience in picking. This space should be kept loose and friable, and when the bed is two or three years old may be utilized by digging in well rotten manure and allowing runners to root therein, when the old rows may be dug under and the bed renewed. In this climate strawberries should be covered with a mulch of marsh hay, corn stalks, straw or any litter that does not lie too close, and is free from weed seeds, deep enough to cover the plants, and not too early in the spring this mulch should be raked off into the space between the rows, and will there do good service in dry weather and be ready to re-cover the plants for late frosts. Care in planting must be exercised so that where pistillate plants are set (and they are generally the most productive) staminates should be set every alternate or at least every second row. Perhaps the best tested varieties at present among the pistillates are Warfield, Haverland and Crescent, and among the staminates Captain Jack, Bederwood and Michael's Early. 'The principal difficulty in getting plants for planting is their liability to heating in transit and thereby they are rendered useless, and it is always in the interest of the planter to get reliable plants as near home as he can for that reason. 
Currants and Gooseberries.-These will grow and fruit abundantly in almost any soil or situation, but no cultivated plant responds more, promptly and generously to manuring and careful attention. One of the easiest methods I have found, however, is to keep the plants well mulched with the sweepings of the chip yard, moving the mulch every now and again to destroy noxious weeds, and seeing well to the pruning out of old bearing branches. The red and white kinds of currants so far give the best satisfaction here, the best being Red Dutch, Victoria, Long Bunch Holland, Cherry, Stewart's \$eedling and White Grape. The difficulty with the black kinds is their unevenness of ripening, almost as bad as the wild black. The latter is a fine flavored berry, and bears very well, and is as large as any under cultivation. Of the cultivated kinds the best are English Black, Lee's Prolific, Black Champion and Black Naples. In Gooseberries, Houghten Seedling, Downing and Smith's Improved, may be recommended for general planting. Some of the larger English kinds may be tried, but most of them are very liable to mildew. This, however, may be checked, if not entirely kept down by liberal sprinklings of $1 / 2$ oz. Liver of Sulphur dissolved in one gallon of water, during the growing season, getting the solution well on the under side of the leaves, and for this purpose a good syringe is the best.

RASPBERRIES.-Remarks made about the native strawberry apply with equal force to the raspberry. No better flavored berry grows, but the softness of the fruit spoils its market value. Under cultivation this is partially remedied, and if the hoe could be kept continually at work thinning out the suckers, I don't know but our native raspberry might be made to supply all market requirements. In small gardens the suckering kinds of raspberries require a good deal of care to keep in order. If planted in rows four or five feet apart and vigorously checking sucker encroachments, no more profitable berry can be planted. Some of the best cultivated kinds, however, need to be covered with soil in the winter and uncovered as soon as danger of frost is over, The Turner 
is the only kind so far tested that succeeds fairly well without covering, but even this will give a far more abundant crop by winter protection. All the black caps require blanketing and are very subject to cane rust or anthracnose. This, however, can be checked, if not eradicated, by liberal doses of Bordeaux mixture during the growing season. The best kinds of tested raspberries are:-Of the suckering kinds, Turner, Cuthbert, Marlboro, Golden Queen ; Of the tip rooting kinds, Shaeffer's Colossa1, Ohio and Nemaha, all of which can be grown successfully with winter protection.

OTHER KINDS.-I would have liked to say something about Dewberries, Sand Cherries, June Berries and Grapes, but might weary you, and perhaps this would be bordering upon experimental work. Permit me, however, to say, that the prospects are very promising that varieties of all these kinds in the near future will be paying products of our gardens. I purposely omitted the Blackberries, as hitherto the best varieties have failed, even with winter protection, to mature paying crops. I must, before I sit down, with your permission, note that some enterprising man who will carefully read up, and who may possess a piece of land that can at will be flooded with water, will some day make a competent living, if not a competence, by planting a good patch of Cranberries, as these can be grown, I am persuaded, as readily here as in the neighboring north-western states.

In conclusion, let me earnestly request all my fellow members of the Winnipeg Horticultural Society to intelligently go to work to make the best of our opportunities in this line, and I can then promise as rich a reward in appetizing fruits as Eden ever grew. 


\title{
Winter Flowering Bulbs,
}

\author{
BY R. ALSTON.
}

Oct. 15th, 1896.

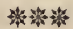

At this season of the year such a subject as winter flowering bulbs ought to be interesting to all lovers of flowers, and especially when our winters are so long and our summers so short, there is no other country where "winter flowering bulbs" should be more highly prized. We are not able to have a plentiful supply of flowers from out doors for a longer period than about three months ; the rest of the year, therefore, depends upon indoor culture of plants and bulbs, if we would have a continuous display of flowers all the year round.

Bulbs, now, are a very important feature in horticulture, and especially the winter flowering ones. Much might here be said about Bulbs,-what really constitutes a Bulb, the different formations of different kinds of Bulbs, what really is a Bulb, and what is not a Bulb, and so on. But my intention to-night is to speak about Bulbs in general,- that is, Bulbs as they are commonly understood by every one.

One of the principal elements of success in the growing of plants and Bulbs is proper soil. Many people have an idea that garden soil is good enough for potting work, but it is a great mistake. No matter how much care and attention is given afterwards, if the soil is not right, the best results cannot be attained. A mixture suitable for Bulbs can be made as follows: Take three parts of old sod, which has been heaped up for at least six months. In that time it will have become thoroughly rotted, and the fibres will all be dead. Mix with this abont one-eighth of leaf mould or well decomposed manure, and one eighth of good sharp sand. This, chopped up fine and thoroughly mixed together, will make a good compost, which will be suitable for almost all kinds of winter flowering Bulbs; so much so that if the Bulbs did not thrive well and give good satisfaction after being 
planted in such a mixture the fault would be due to some other cause than the soil.

The next and most important thing to insure success with winter flowering Bulbs is to get the best Bulbs possible, even at an advanced price, then half the battle is fought. Never be tempted by cheap collections of Bulbs, such as are offered in many of the catalogues and advertisements which may come before your notice from time to time. Fancy a seedsman offering a collection of $10 \mathrm{Bulbs}$ for 25c., postpaid, and this collection to contain 2 Hyacinths, 1 Easter Lily, and 7 other Bulbs all different. The same seedsman will list Hyacinths at from 10c. each to $20 \mathrm{c}$. each, and Easter Lilies from $10 \mathrm{c}$. to $35 \mathrm{c}$. each. Another collection will contain 25 winter flowering Bulbs, postpaid, for 50c.-this collection to contain 2 Easter Lilies, 3 Hyacinths, 4 Narcissus, 6 Tulips, and 15 other Bulbs. And again, another collection will contain 60 Bulbs, postpaid, for $\$ 1.00-$ this collection, of course, would contain valuable bulbs in proportion to the price, the same as the first mentioned collections. I have often had to laugh when these collections, which have been received by those who have been tempted to send their money for them, have been brought to me for the purpose of having them potted up. The size of the bulbs was in most cases ridiculously small, so much so that I have often persuaded the owners of them not to go to the expense of potting them up, as it would certainly have been a waste of money on their part, and likely a customer lost to some dealer who handles good Bulbs at a reasonable price. Many are the persons who have been discouraged on account of their Bulbs not flowering, when they have thought it has been the fault of their wrong treatment, at the same time the Bulbs they had secured had not the flowering ability in them, and therefore would not flower under any circumstances.

The next matter of importance is the varieties of Bulbs best adapted for amateurs and window culture. Atter a long experience amongst Bulbs I would say that the following are $t$ le best and most advisable. I will mention them as near as 
possible in rotation as they should be handled at the different seasons, that is, some should be planted in the spring, others at midsummer, and a large majority in the fall and early part of the winter, so as to bring them into bloom at different times through the winter.

1st. Cyclamen, which is really a bulbous plant.

2nd. Tuberoses, (the Pearl or Excelsior Pearl."

3rd. Freesia Refractra Alba.

4th. Lilium Harrisii, or Easter Lily, Lilum Rubrum, Lilium Album, and the Calla Lily.

5th. Roman Hyacinths, or Small Flowering.

6th. Dutch Hyacinths, that is the large flowering Hyacinths. I would here advise all who are not well experienced in the growing of Dutch Hyacinths to be sure and grow the single varieties, as they are much easier grown. They force out of their season better than the double ones, and therefore are sure to give better satisfaction.

7 th. Tulips, both single and double.

8th. Narcissus, single and double, including the Chinese Sacred Lily.

9th. Ixias and Sparaxis.

10th. Crocus.

11th. Snowdrops.

12th. Oxalis, the white, pink and yellow.

And there are many other varieties of Bulbs that will flower in the winter months which will be found in any Bulb catalogue for those who wish to go in for a greater variety than the above, but I think amateurs would have better success if they would go in for good quality rather than innumerable varieties.

Our next step will be how to treat and manage the different varieties of Bulbs above named. We will first take the Cyclamen. These are raised from seed sown either in October or November, and as soon as the seedlings are large enough they should be transplanted to small pots, and then re-transplanted from time to time through the summer, until you have them planted in a 6 -inch pot. They ought to be 
into this size pot by the month of August, and by the end of October they will be full of buds and flowers-that is, if they have been rightly managed. The whole secret of successful Cyclamen culture may be summed up in a few words, as follows:-Constant and unvarying heat, a moist atmosphere, and abundant supply of water without stagnation, free circulation of air, avoiding cold draughts, light in winter and shade in summer, with freedom from insect pests. A Cyclamen Bulb should never be planted more than half its depth in the soil, as the crown should always be kept above the earth.

The Tuberose.-This is not quite as popular as most other winter flowering Bulbs, on account of their uncertainty to bloom after being taken into the house. For winter flowering they should be planted in pots any time from June to August, and the pots sunk outdoors; they should then be carefully watered until the nights begin to get cold, when they should be taken into the house and placed in a sunny window, and from this on they should be kept pretty warm, as otherwise they will not perfect their flowers. If properly managed each Bulb will send up a stem bearing a dozen or more of the most beautiful pure white, wax-like, sweet scented double flowers.

The Freesia Refracta Alba are splendidly adapted for winter, and are becoming one of the most popular of winter flowering Bulbs. These Bulbs can be secured about July, and should be planted in that month in order to have them in bloom for Christmas; on account of the Bulbs being so small and the foliage being so narrow four or six can be planted in a 5-inch pot, and about 1 inch deep. They commence to grow at once after being planted, and can be placed in the window amongst the other plants. If these Bulbs are planted successively from July to November, they will give a succession of bloom throughout the winter. The flowers of the Freesia are very beautiful and fragrant, and keep a long time after being cut, this making them very valuable and pleasing to the grower. 
Lilium Harrisii, or Easter Lilies, are so well known that they need no description. The Bulbs should be planted in 6 or 7 -inch pots, according to the size of the Bulbs. In potting fill the pot about half full of earth, on which place the Bulb; leave in this state, with the exception of watering occasionally, until it has grown above the edge of the pot, then fill the pot with earth. No special treatment is necessary after this; oply treat as you would any other plants. One thing might be of importance to the amateur, and this is, the cooler they are grown the dwarfer they will be when in bloom, and this makes a much prettier plant. Easter Lilies can be had in bloom almost any time of the year by a succession of planting, but for Christmas flowering they should be planted in July.

Lilium Rubrum and Lilium Album are very pretty Lilies, and should be treated the same as Easter Lilies, with the exception of the time of planting. They should be planted in March and plunged out-doors in the pots as soon as the weather is suitable. An occasional watering will be all that is necessary till the fall, when they should be taken indoors before the approach of cold nights. These Lilies will then bloom in the months of September and October.

The Calla Lily is another of the well known plants that need no description; but there is one great mistake which is made by almost all amateurs in the growing of this Lily, and that is keeping them growing all the year round without any rest. To grow and flower a Calla Lily with success it must be treated as follows: If the Bulb is large enough to flower or has flowered, it should be dried off for about 3 months, this is done by withholding the water, then the Bulb will lose all its leaves and roots. At the end of the three months, take the Bulb out of the old earth, and pot in a 5-inch pot, and start into growth by giving water; after the Lily has given one flower it could be potted into a 6-inch pot, then treat as other plants through the season, giving them rather more water than most other plants, especially in the flowering season. 
The Roman Hyacinths are a smail class of Hyacinths, and are very useful on account of their earliness. These Bulbs can be secured in August, and if planted at once may be had in bloom by the end of October, thus being two months earlier than the Dutch Hyacinths. These are planted three Bulbs in a 5-inch pot, or six Bulbs in a 6-inch pot, and when in bloom make a very pretty show, especially, being so early in the winter.

The Dutch Hyacinths, Tulips, Narcissus, Crocus, Snowdrops, Ixias and Sparaxis, are all treated in about the same manner. These Bulbs should be planted in pots not later than the month of October to have the very best results, though they are often planted as late as December. The Hyacinth should be planted with about one-third of the Bulb out of the earth, but the other Bulbs mentioned here should be planted from one to two inches deep, according to the size of the Bulb. These Bulbs, after being potted, should be watered at once, and placed in a cool cellar, and covered with about four inches of sand or coal ashes ; in this condition they will make but little growth, but make an abundance of roots ; after one month you may bring some of the pots to the light, and for the first day or two shade them with thin paper; after this you may force them all you wish, and treat them as you would any other plant, giving them rather more water than you would ordinary house plants. If you do not wish to have all the Bulbs flower at the same time, you can hold them back by leaving them in the cool cellar, and bring them up as you need them. In this way you may have a succession of flowers from the Bulbs you planted all in the same day.

If you wish to grow Hyacinths in water, I would advise that the very best of Bulbs be secured, as second-class Hyacinths never do well grown in water. To grow them in water, fill the glass so that the Bulb will almost touch, set in a dark cool place as before described; if the water becomes foul clean out the glass and replace the Bulb; always keep water enough in the glass to almost reach the 
Bulb. It is advisable to put a piece of charcoal in the glass, as this helps to keep the water pure.

The Oxalis are beautiful ever-blooming plants, ráised from bulbs. The varieties best adapted for winter work are the white and pink, and also the Bermuda Buttercup, which is a yellow variety. These Bulbs can be planted at any time of the year, and are very suitable for hanging baskets. No Bulbs can give better satisfaction to the amateur, as they are a glow of beauty and a source of great satisfaction almost the whole year round.

There is one other variety which I have not mentioned particularly, and that is the Chinese Sacred Lily, (Narcissus Orientalis). This should not be overlooked by any amateur, as they are so easily managed, and can be grown in almost any kind of ornament you may like to have on your table. They are planted in clear water with a few pieces of charcoal at the bottom, and a few pebbles to hold the Bulb firm. These Bulbs, at this season of the year, take from six to eight weeks from the time of planting to the time they are in full bloom. It is not necessary to place these Bulbs in the cellar, but place them in the light as soon as planted. One thing is of importance, that of keeping them as near a window, and in as cool an atmosphere as possible, by so doing the plant will keep dwarf and be stronger at the time of flowering, and thus have a much handsomer appearance.

\title{
20 \\ Growing Flowers in the Home,
}

\author{
BY M. M. HOLIDAY. \\ Nov. 19th, 1896.
}

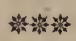

My attention has been given mostly to plants requiring little care, owing to cramped facilities and lack of time.

I have grown a number of Geraniums, and with few exceptions had success. Pot with good soil mixed with sand, 
Keep fairly moist during the winter. I find they do better in a moderately heated room than an over-heated one. I seldom feed or sprinkle them; they always grow well and are in a healthy state, having bloom throughout the winter. I had a Geranium, (Countess of Derby), it was four years old. For three years had it in the same pot (6 inch) and never changed the soil, occasionally when washing the bird pan I used the solution, but nothing else ; also during the fall and winter I cut off slips, and about the end of January I gave it its final cutting down to six or eight inches. It always looked healthy and bloomed well all summer. This shows the Geranium will thrive when first potted in good soil for a long time without frequent repotting.

Fuchsia-I have always had success with. During the blooming season in spring and summer with me, I kept them always wet and sprinkled them once a week, late in the fall cut them down and put them away in a fairly dark, cool place (not having a good cellar) giving water enough to keep them alive. In spring repot and gradually bring them to the light. I grew mine in a north window, and they did beautifully.

Roses.-I have only tried a few Tea Roses; they do not thrive under house and window treatment with me; the growth is too slow. I am under the impression they require under heat.

PALMS-I have cultivated the last two years. The Kentia Belmoreana and Kentia Fosteriana are both hardy sorts for the house. Mine are growing well. I give them plenty of water and occasionally a weak solution of cow manure. Sponge off the leaves once in a while, the oftener the better. The Dracaena Indivisa treat the same as the Kentia. The Umbrella plant requires an abundance of water. I have found them very easy to care for. Mine was badly pot bound so I separated the roots and repotted in good soil, making three good pots full out of one. I watered them freely, and they have made rapid growth. Palms being used as ornamental plants in the house are deprived of light. I 
certainly think they should be changed about and given direct light part of the time. The Dracaena especially, if deprived of light very long, the leaves begin to dry off at the ends. I noticed in The Family Herald, just lately, that the greatest Palm fancier in London has discovered this; that the leaves of the Palms should be washed not with pure water, but milk and water, which has a wonderful way of preserving them and preventing the appearance of the brown spots which are so disfiguring.

The Anemone Japonica I have grown very successfully. The blooming season is about September. The flowers resemble the wild rose, only being waxy white and larger. After blooming I kept them in an east or north window to rest, giving only enough water to prevent wilting. In' the spring, about April, transplant in good soil, separating the roots, keep moist and in an east window for a time. I find they do better with little sun. During the summer put them out in the garden, sink the pot in a half shaded place, when the buds are showing bring them indoors to the window.

\section{I have grown a few bulbs-}

Hyacinths. - Pot in good soil mixed with sand, plant deep, the head of the bulb being only at the top of the soil, water and set away in a dark cool spot in a cellar for six or seven weeks, keeping them only damp. When up an inch or two bring them to an east window. Do not expose to the sun for some time until the flower stem is well up as the sun is too hot for them against the window, the buds burst into bloom before the stem can be seen. The Harissii, or Easter Lily, I plant the same as the Hyacinth, it does not require to be shut away from all light. Keep in a moderately warm place until it begins growth then bring it to the sun and keep moist. The Daffodil I treat the same as a Hyacinth. The Freezia, Allium and Tritilea start growth earlier. When up about three inches bring them to the light until the leaves get a deep green, then they are strong enough to stand the sun. 
After the bulb season, begins the seed planting for summer. I have been successful with the Annuals, have grown Asters, Verbenas, Phlox, Stocks, Petunias, Gaillardia, Marigolds and Pansy. With exception of the Pansy start them about the middle of March. Pansy seed should be planted at least a month earlier. Prepare good soil with plenty of sand, sift in a fine sieve, put the coarse pieces at the bottom of your boxes, an inch deep, fill up with fine soil and press firmly, in putting in the seeds be careful not to have them one on top of the other. Cover well with a fine soil, press lightly and sprinkle with tepid water with a small brush. Cover with a glass and put in a moderately warm place for three or four days, then expose them to a south window. Let the glass remain on, when you see the soil being forced up remove it. The Petunia is an exception, the seed being so small and delicate great care must be used. Sprinkle very lightly with soil, moisten, keep covered with the glass for some time. They are very slow in germinating. Have ready more boxes for transplanting. When the seedlings have grown about four leaves, use a table fork to dig and separate them, plant again about two inches apart, keep moist and cover with a paper while the sun is on them. When strong enough, expose to full light and sun. I can highly recommend leaving the boxes out of doors for two weeks or so previous to disturbing them. The plants are strong and very seldom wilt when set out. The Stocks have not proved as great a success, they germinate and grow well. Many of them look strong seedlings and all of a sudden are wilted down. They have rotted from the roots. I often lose them the same way after being transplanted. I do not know how to account for this failure. 


\section{Prairie Flowers Suitable for Cultivation in Gardens.}

BY REV. W. A. BURMAN.

April 12th, 1897.

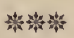

The praises of our prairie flowers have been sung by many a traveller, and justly so, for he must be dull indeed, who can travel over our vast plains, resplendent with the colours of millions of flowers, and not be obliged to confess their beauty. To the immigrants from eastern Canada, still more to those who have crossed the Atlantic to find a new home here, the prairie flowers are very welcome. They are somewhat of a cure for homesickness, and help to reconcile many a struggling man, and still more lonely woman, to the new home.

But our purpose at present is to see how we can best use these gifts of God's kind hand, to beautify our homes in this new land; how we may best utilize our native flowers, so that they may not altogether "waste their sweetness on the desert air." Though this is my purpose, I had better confess that personally, I never find flowers look just as beautiful anywhere as in their native haunts. There is something in the fitness of their natural environment, which gives to them a peculiar charm, altogether or greatly lacking, when we have removed them to either house or garden.

In speaking of the fitness of wild flowers for cultivation, we have to consider several points :

1st. The beauty and value of flowers.

2nd. The conditions necessary to ensure its successful culture.

3rd. The objections, if any, to its introduction. 
1st. We may say regarding the beauty and value of our prairie flowers, that much must depend upon the standard of excellence, or what we think worthy a place in our gardens. Herein there may be much difference of opinion, for tastes differ. But the fair way seems to be, not to compare our wild flowers with those which have for generations received assiduous care, and show us now the effects of that "higher culture," of which we hear so much in other directions.

Many of our wild beauties would, even with them, be able to hold their own-but the test is scarcely a fair one. We must look at the flowers or plants as we find them, and then ask if, in their native beauty, either singly or in masses, they are likely to prove worthy of places among what we may call the more highly polished products of the horticulturist's skill.

Then of course we must bear in mind the probable effects of cultivation, and especially of careful selection of hybridization upon the prairie flowers. While in some cases these fail to "improve" the plants under experiment, very often most valuable results are obtained.

In the marvellously beautiful Calceolarias now in cultivation we have examples of what may be done by hybridzation, for the originals were plants of different species with very small red and yellow flowers, from South America.

Similar results might be obtained here, and without doubt there would be a vast improvement in many cases as to size, colour and form, under careful selection of seedlings and suitable cultivation.

2nd. The conditions necessary to successful culture. These must be considered, and it is obviously of little practical use to consider any plants that require conditions not easily obtained. In the following list I have therefore left out of consideration many plants which could not easily be grown in an ordinary garden. We might mention among others the beautiful Pyrola or Wintergreen, which thrives only in damp woods, as also several orchids which require the 
same conditions, or the lovely white Water Lily, which requires to be grown in water. The plants hereafter named should grow in any ordinary garden. Some may require attention as to shade and moisture.

3rd. Any plants that might be very objectionable, either because of some poisonous or irritating quality, or because they become garden pests, must be excluded.

I may add that while nearly all the plants are found upon the open prairie, I did not feel restricted to such, and so have introduced some few from the woods.

I shall now give the names of about 100 species, differing indeed as to beauty, but all more or less desirable for garden culture. Those specially desirable will be noted as we proceed.

I give them according to the natural orders to which they belong, and in most cases add their common, or some appropriate names. I do not of course pretend to give all that might be named, but simply such as occur to me. *

I. The order Ranunculace furnishes a few species of particular beauty, viz:

1. Anemone Patens Var Nutullii._- "Pasque flower" or "Crocus." This lovely flower, the first to greet us in the spring, and commonly, though wrongly called the Crocus, needs no description. It is a beautiful object wherever grown, and like most Anemones, easily cultivated.

2. Anemone Diebotoma.-Round-headed Anemone, and a double form of the same. Pure white.

3. Aquilegia Canadensis.-Columbine.

4. Aquilegia Chrysantha.-Yellow flower Columbine. These are exceedingly beautiful. The former, crimson and yellow, grows throughout the prairie region in cool woods and glades. The latter a delicate shade of yellow, in the foothills of the Rockies.

5. Clematis Verticillaris.-Purple Virgin's Bower.

* About 60 of the plants named were exhibited by the lecturer. 
6. Clematis Virginiana.-White Virgin's Bower. Better known, perhaps, as 'Traveller's Joy. The former is found in rocky woods, the latter in low ground and bluffs; both are elegant climbers.

II. Papaverace A.-(Poppy Fámily).

7. Sanguinaria Canadensis.-Bloodroot. Found in the Pembina Mountains.

III. CAPPARIDACEA.-(Caper Family).

8. Cleome Integrifolia.-Spider Flower. An attractive purple flower. Plentiful in some localities. Amongst others on main road, six miles north of Winnipeg.

IV. VIOLACEA (Violet Family).

9. Viola Delphinifolia.-Bird foot Violet. Flowers fine, large, deep blue, but odourless. Common on dry knolls. Leaves deeply cut, hence its name.

V. Malvacez.-(Mallow Family).

10. Malvastrum Coccineum.-False Mallow. A cow plant, with pink to red flowers. On dry soil.

VI. Celastracez.-(Staff Tree Family).

11. Celastrus Scandens.-Bitter sweet. Valuable for its clusters of deep orange berries in winter. A climber, requiring shade.

\section{VITACEA. (Vine Family.)}

12. Ampelopsis quinquefolia. - Virginia Creeper. Needs no description. Excellent for walls or verandahs with a southern aspect. Easily transplanted.

VIII. LEguminos瓜. (Pea Family.)

13. Amorpha fruticosa.-False Indigo.

14. Amorpha canescens.-Hoary lead plant. Both these have spikes of purple flowers. The former is a shrub 3 to 6 feet; the latter 1 to 3 feet, with hoary leaves. No. 13 grows on river banks ; No. 14 on dry soil.

15. Astragalus bisulcatus.-Milk Vetch.

16. Astragalus hypoglottis.

17. Astragalus caryocarpus._-"Ground Plum." "Buf- 
falo Bean." Low growing plants with purple pea-like flowers. No. 16 is very common and blooms nearly all summer. No. 17 has pods the size and shape of plums.

18. Hedysarum boreale. (Hedysarum $=$ Sweet Odour.)

19. Hedysarum albiflorum.-White flowered Hedysarum. Produce spikes of purple and white flowers respectively.

20. Oxytropis splendens. Plant 6 in. ; silvery ; flowers deep blue.

21. Oxytropis lambertii.

22. Tathyrus venosus. "Everlasting" Pea. A climber, purple flowers in clusters. Very common.

2 23. Petalostemon candidus. White prairie clover.

24. Petalostemon violaceus. - Purple prairie clover. Flowers in elegant cylindrical heads.

25. Thermopsis rhombifolia. Valuable for its yellow flowers, about the size of those of the garden pea. Height one foot. Perennial.

IX. Roseace Á. Rose Family.

26. Rosa blanda. Wild rose. The species here referred to is the one growing in bluffs, etc. Well suited for low hedges. The low-growing prairie species is to be avoided, as it makes too many suckers.

27. Amelanchier aluifolia.-June berry. Saskatoon. A favorite shrub. Flowers very beautiful, white and odourous.

28. Spirea Salicifolia.-Willow-leaved meadow sweet. A graceful shrub, with clusters of lovely pink and white flowers. Quite equal to some imported Spireas. Common everywhere.

29. Geum Triflorum.-Three flowered Avens. Wellknown from its three purple flowers on each stem. Seeds in feathery clusters are as pretty as the flowers.

X. Saxifragace A. - (Saxifrage Family).

30. Parnassia Palustris.-Grass of Parnassus. Flowers white with greenish centres; much admired; needs wet soil.

31. Ribes Aureum.- Missouri or Flowering Currant. Found on South Saskatchewan. A shrub with bright yellow and very fragrant blossoms. 
XI. Onagrace

32. Epilobium Spicatum.- Great Willow-herb (Fireweed). Grows around and in burnt woods. Flowers showy purple in large spikes.

33. Gaura Coccinea.-Gaura. A pretty delicate plant, suitable for rockeries and dry places; grows in gravelly places. Primrose.

34. Enothera albicaulis. - White-stemmed Evening

35. Enothera serrulata. - Small Evening Primrose. The former with large white flowers, the latter yellow.

XII. Cucurbitaces.--(Gourd Family).

36. Echinocystis lobata.-(Wild Cucumber). Very popular as a climber for verandahs, etc. Graceful and luxuriant. Flowers in large clusters. Fruit like small prickly gourds.

XIII. CACTACEA.-(Cactus Family).

37. Mamillaria viviparia.-Flowers scarlet.

38. Opuntia Missouriensis. - (Western Prickly Pear). Flowers light yellow and very fine.

XIV. CAPRIFoliace死.-(Honeysuckle Family).

39. Lonicera Sullivantii.

40. Lonicera Glauca.-Smooth Honeysuckle, suitable for shrubberies.

41. Diervilla trifida.--Bush honeysuckle.

42. Viburnum lentago.-Sheep-berry.

43. Viburnum opulus. - High bush cranberry.

XV. Rubiace. (Madder Family.)

44. Galium boreale.-Northern bedstraw. A common plant. Flowers white and scented, in large clusters.

XVI. Composites. (Composite Family.)

This large family contains many of our most striking flowers, which are well worthy of cultivation. Amongst the best are the numerous asters - the sunflowers, blazing stars and gaillardias.

45. A plopappus spinulosus.-Grows on gravel ridges. Flowers yellow. 
46. Arnica alpina.-Alpine Arnica. On dry hills.

47. Arnica cordifolia.-Heart-leaved arnica.

48. Aster lindleyanus.-Lindley aster. Blue.

49. Aster lævis. - Smooth aster. Common blue.

50. Aster multiflorus.-Many flowered aster. White. One foot high.

51. Aster novæ angliæ.-New England aster. Large, purple.

52. Aster paniculatus.-Tall, white.

53. Aster ptarmicoides. Dwarf, white.

54. Aster ptarmicoides var lutescens. Yellowish aster. A pale yellow form of 53. Rather rare.

55. Chrysopsis villosa. - Dwarf. Flowers a golden yellow. Suitable for rockeries, as is also No. 45.

56. Cnicus undulatus. - Prairie thistle. Large, purple.

57. Echinacea augustifolia.-Purple cone flower.

58. Erigeron glabellus. - Fleabane. Flowers large white.

59. Gaillardia aristata.-Gaillardia. A very handsome flower. Some forms quite equal to those now in cultivation.

60. Helenium autumnale.-Sneezeweed. Flowers elegant in form ; yellow. Grows in very wet places.

61. Helianthus nuttallii.-Nuttall's Sunflower.

62. Helianthus gigariteus.

63. Helianthus rigidus.

64. Helianthus doronicoides.

All the sunflowers are handsome. Of these named Nos. 61 and 62 are perhaps the best.

65. Heliopsis scabra.-Ox Eye.

66. Prenanthes alba. - Rattlesnake root.

67. Prenanthes raccinosa.

68. Solidago Missouriensis. - Golden Rod. Several other common species are worthy of cultivation. Vary in height and size of flower cluster.

69. Liatris scarriosa.--Blazing Star. Very handsome; heads large; purple, in long spikes; a perennial; does well under cultivation. 
XVII. Lobeliace. - (Lobelia Family.)

70. Lobelia Kalmii.-Kalim's Lobelia. Bright blue.

71. Lobelia spricata var luitella.--Spiked Lobelia, lilac.

72. Lobelia Dortmanna. - Dortmanna's Lobelia, lilac. The above species are all pretty; require damp soil.

XVIII. Primulace 死.-(Primrose Family).

73. Dodecatheon Meadia.-American Cowslip. Flowers small but pretty, purple, moist places.

74. Primula farinosa.-Birds-eye Primrose.

75. Steironema ciliatum.--Yellow loosestrife. Showy flowers; yellow ; common.

XIX. Gentranace. (Gentian Family.)

76. Gentiana affinis.

77. Gentiana Andrewsii.-Closed Gentian.

78. Gentiana Crinita.-Fringed Gentian.

79. Gentiana Alba.-White Gentian. The above species of Gentian represent four different types and are all handsome. Nos. 76 to 78 are blue, No. 79 white.

XX. Borraginace.a.--(Borage Family).

80. Tithospermum canescens.-Puccoon "Cowslip."

XXI. SOLANACEA.-(Nightshade Family.)

81. Physalis Grandiflora.-Wild Ground Cherry.

XXII. Scrophulariacesi.-(Figwort Family.)

82. Castilleia coccinea.- Painted cup. 'Flowers surrounded by brightly colored crimson to orange tracts ; very attractive ; common.

\section{"Scarlet tufts}

Are glowing in the green like flakes of fire, The wanderers of the prairie know them well, And call that brilliant flower the painted cup."

-Bryant.

83. Gerardia tenuifolia.-Gerardia. A delicate plant, said to be parasitic, $1 \mathrm{ft}$. high; grows on gravel ridges. Flowers pink- $1 / 2$ in. long.

84. Pentstemon confertus var atropurpureus.- Purple Beardtongue. Purple Pentstemon. 
85. Pentstemon cristatus. - Crested Beardtongue.

86. Pentstemon gracilis.-Graceful Beardtongue. Pentstemons are among our most handsome flowers. The species named above are well suited for small gardens. Height 6 to 12 in. Nos. 85 and 86 have lilac flowers. No. 84, purple. Common through prairie region.

XXIII. Labiate. (Mint Family.).

87. Lophanthus anisatus. - Wild Aniseed.

88. Monardar fistulosa var mollis.-Horse Mint.

No. 87 has long spikes of purple flowers. No. 88, heads of mauve flowers. Both strongly aromatic.

89. Physostegia virginiana. False Dragonshead. Very beautiful. Flowers showy rose or flesh colour. Prefers shade and damp ground.

XXIV. ORCHIDACEA. (Orchid Family.)

90. Cypripedium Regina.-Pink Lady's Slipper.

91. Cypripedium parviflorum.-Yellow Lady's Slipper. "Mocassin Flower." It is needless to dwell on the beauty of these. Both are well known, and are as lovely as any orchid grown. They thrive in gardens with care.

92. Orchis rotundifolia.-Round leaved Orchis. Interesting and pretty. Flowers very delicate.

XXV. IrIdaces. (Iris Family.)

93. Sisyrincehium Bermudiana.-Blue-eyed Grass.

XXVI. Amaryliddaces. (Amaryllis Family.)

94. Hypoxys erecta.-Yellow Star Grass.

XXVII. LILIACE底.

95. Allium Stellatum.-Wild Garlic, pink.

96. Lilium Philadelphium.-Orange Lily.

97. Maianthemum bifolium. Two-leaved False Solomon's Seal. Sometimes wrongly called Lily of the Valley.

98. Smilacina stellata.-False Solomon's Seal.

99. Trillium cernuum.-Trillium.

100 Zygadenus elegans.-No English name. Flowers white or creamy with delicate green shadings, well named elegans, its long spikes of pretty flowers forming a beautiful picture amid the waving grass. Grows on rich prairies. 
The list might be greatly extended, but the names given will suffice to give some idea of the wealth of our western flora in plants worthy of cultivation, and some of them of remarkable beauty. It will be noticed that none of our beautiful ferns are included. Sometime, perhaps, in the near future, Winnipeg may possess a botanical garden in which all these and many other of nature's gems, may be brought together to demonstrate that this adopted land of ours is not a wilderness, but a land of flowers.

I have spoken of the value of these prairie flowers to the homesick immigrant. Many can say with Campbell,

"Ye field flowers ! the gardens eclipse you 'tis true;

Yet, wildlings of nature I dote upon you,

For ye waft me to summers of old,

When the earth teem'd around me with fairy delight, And when daisies and buttercups gladden'd my sight,

Like treasures of silver and gold."

\section{$\because$ \\ Report of the Executive Committee.}

类数粠

Presented at the Annual Meeting in the City Hall, Winnipeg, February 18th, 1898.

竝数

To the Members of the

\section{Manitoba Horticultural Society:}

During the twelve months last past there has been a considerable change in the Society's method of holding meetings. Instead of monthly meetings which did not excite very general public interest, and which at the best could only benefit a limited circle in and about Winnipeg, it was decided to hold fewer meetings of that class and give special attention to an annual gathering in the month of February, to which members outside the city should be specially invited, and with a 
view to which reduced rates of railway travel should be secured.

During the past twelve months two public meetings of the Society have been held and five meetings of the Executive Committee. At the first public meeting, which was held in February, Mr. S. A. Bedford, of the Brandon Experimental Farm, gave an address on "Shrubs and Perennials," and at the second in April, the Rev. W. A. Burman read a paper on "Prairie Flowers suitable for Cultivation." This paper was illustrated by an herbarium of over a hundred specimens, representing some sixty varieties. Both papers were of a very useful character, and the interest taken in them was evident from the lively discussion which followed each.

The Executive Committee has given a considerable amount of attention during the year to making the advantages of the Society known throughout the country, and while these efforts have already borne fruit, it is hoped that a still greater harvest is to be reaped in the time to come. The number of paid-up members now stands at 50, which of course is a small number as yet, but is a decided advance on 19 , the number we had a year ago. Most of these became subscribers as the result of a personal canvass conducted by the members of the Executive, but a good many came in as the result of a circular of invitation sent out last spring.

The Executive offered as a bonus last spring to all members a choice of any one parcel from among the following, thus :

Parcel No. 1.-Six Turner (red), and six Golden Queen (yellow) Raspberries.

Parcel No. 2.-One each of Dielytra Spectabilis and Perennial Phlox.

Parcel No. 3.-One Geranium, one Fuchsia, one Foliage plant, one Chrysanthemum, one Rose, all named varieties.

Forty-one parcels were sent out in terms of this offer; eight of the raspberries, twelve of the perennials and twentyone of the greenhouse plants. 
The Executive appointed a deputation to wait upon the Government with a view to securing a grant to assist in the publication of its papers. The deputation presented its case to the Minister of Agriculture, and there is good prospect that a grant will be made during the coming session of the legislature.

The Executive offered two prizes for named varieties of prairie flowers at the last Winnipeg Industrial Exhibition. There was brisk competition and the prize winners richly earned their honors.

A friendly letter has been received from the secretary of the Minnesota Horticultural Society, proposing that this Society affiliate with theirs. This proposal is recommended to your favorable consideration.

Thus far the report has confinea itself to what has been done during the past year. But something more than that may fairly be required of us. We must look into the future and endeavor to map out some of the lines of usefulness which the Society may most profitably follow during the year or years to come. Of these there are several which are already pressing themselves upon our attention.

I mention first, not because it is of most importance, but because it must be attended to without delay, the question of the revision of the prize list of the Winnipeg Industrial Exhibition Association. There is now in the hands of our secretary a letter from the manager of the Exhibition, asking for co-operation in the matter. We assisted last year at the request of the Association in the same line, and barring some hesitation about spending as much money as we thought horticulture was entitled to, we found the directors very ready to meet our wishes. At their suggestion we appointed a delegate to be the official representative of our views in any matters that needed to come before the Exhibition Association. This matter of arranging the prize list is in the main a matter for experts and professionals, and we shall be glad to have any suggestions from persons interested, and will 
give to any reasonable proposals all the weight of our influence.

Another matter and one of very great importance is that of publication. We have no desire to benefit merely those who live in and about Winnipeg, and the comparatively small proportion of the flower-lovers in the west who are able to attend our meetings, and we wish by the publishing of our papers to extend our usefulness to a much wider area. We have now material on hand for an ordinary sized pamphlet of about forty pages, and the record of this meeting will very likely make about as much more. We cannot publish this without assistance from the Government, assistance which I am glad to know we are very likely to receive. The large grants bestowed upon the Horticultural Societies elsewhere, makes our request for a hundred dollars seem entirely insignificant. If we are able to realize our plans in this direction, our work ought to prove a valuable supplement to the good work which is being done on the western experimental farms.

The distribution of plants is a project that ought to engage our attention. We made a beginning last spring and with added experience hope to do better this year. These plants are an inducement in many cases to bring in our members, but what the Society regards as of greater importance, is that some of the classes at least will always mean the introduction of new and valuable plants that are sure to do well in this country.

Perhaps the most important question of all which lies before us in the immediate future is the question of affiliation. The letter from the Minnesota State Society has already been mentioned. The neigliboring United States of Minnesota and Wisconsin, North and South Dakota, have much more in common with us from a fruit-growing point of view than any of the provinces of Eastern Canada, where the climate and other conditions are so different, and this proposal of the Minnesota Society, backed up as it is by the paper on the history of that Society, which Mr. Latham has kindly sent, ought certainly to secure the most attentive and favorable 
consideration. It would certainly be proper also to open correspondence with the Ontario Association and secure some basis of mutual recognition and friendly co-operation in our respective spheres. But so far as affiliation is concerned, the most natural and intimate relation of all for us is that which we ought to seek with a sister society which has recently been established within our own province, in Brandon. Whatever we do in the matter of societies beyond our own borders, we must in any case make approaches to this sister society with a view to a harmonious interchange of facts and ideas.

All of which is respectfully submitted,

ANDREW B. BAIRD,

President.

\section{DISCUSSION.}

MR. BEDFORD. I am glad to see the reference to the Brandon Society in the report of the Executive Committee. Last year the directors of the Horticultural Society in Brandon persuaded the directors of the Western Fair to take up this question in a proper manner. The directors of the Association sent in their prize list to the Horticultural Society of Brandon. The result was that the Society drew up a prize list and had a fine display, one hundred times better than it was before. I might say that it was largely due to the members from Winnipeg, Mr. Alston and others assisting, that we had such a success. We feel that we did much in Brandon besides encouraging this display in getting the people to go on with the work. I am sure that the Brandon Horticultural Society will be happy to join with you in the work if it can.

Moved by Mr. A. McKay, seconded by Mr. S. A. Bedford, that the report of the Executive be received and adopted. Carried. 


\section{Organized Horticulture in the North- West.}

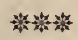

Dear Friends of Horticulture, 500 miles to the Northwest:

In the early days of the Society you have formed it may be of interest to you, and perhaps of some value, to know something of the history of the sister association 1ying nearest to you, I believe, in miles, of any kindred organization. On the fourth day of October, 1866, a dozen of the fruit growers of southern Minnesota, being met incidentally at the State Fair, organized what they called at that time the "Minnesota Fruit Growers' Assnciation." Pomology in Minnesota, was, at that early uay, comparatively new, although some varieties of apples brought from the eastern States were in bearing, enough, at least, to make an exhibit at the fair. The following year the name of the society was changed to its present one, and its membership was very much increased. The writer of this article had the pleasure of meeting with the Society for the first time in what might be called its third annual meeting, held in St. Paul in 1869. At that time the membership had increased to forty-two, and included the principal nurserymen of the State and many other leading men, mainly in and about the twin cities. The writer also had the honor of acting at that meeting as secretary, making a long-hand report of the proceedings. This was the first published report of any meeting of the Society, and the expense was met from the pockets of the members. The sessions were held thereafter annually without financial assistance from any source, except as the members contributed themselves, until the year 1873, at which time the legislature of the State made provision for printing annually 2,000 copies of the report, provided the expense of publication did not exceed $\$ 500$. I think at that time also arrangements were 
made for printing the back reports of the Society, so that the first printed volume contained the reports of the first six years.

The membership slowly increased, and the interest continuing, in 1881, eight years after the first public publication, the legislature made an appropriation of $\$ 1,000$ annually for the support of the Society, besides increasing the printing fund to $\$ 750$ per annum. At this time the roll showed fiftynine annual members and four. life members. The next ten years of the Society was marked by steady growth, until in 1891 the membership had increased quite materially, then numbering 195 annual members and 39 life members. Since then the interest in the work of our Association has steadily developed and the number of those who labor witl us increased, until at the last annual meeting the secretary was able to report a membership of over 700, of whom only 55 were life members, making the Minnesota organization the largest of its kind in the United States, although not the largest in America, as your sister province, Ontario, can boast an organization, working on a plan similar to ours, I believe, of about 2,000.

The method in which the report of our Society has been published the last three years has had much to do with the growth of this work. During this period our report has been sent out in monthly sections, and at the end of the year these hare been bound, with the journal of the Society, list of members, etc., together making the annual report of the Association, a volume of something over 500 pages. We have found this method of sending out our reports in many ways a great advantage, the effects of 'which have been felt very widely throughout the State. The interest in our work has communicated itself to the general press, and especially to the agricultural press of the State, and through the farmer's institutes as a co-worker, we have been able to reach in a general way a very large number of the planters of the Northwest. In this term Northwest might be included our own State of Minnesota, the two Dakotas and your province, 
all of which section has been more or less tributary to our Association, and it has been our purpose to be helpful as far as possible to all this region.

At the entrance of your Association into this field we welcome you most heartily. The difficulties which are being encountered in Minnesota are very similar to those of your section, and you will be stimulated by those very difficulties in prosecuting with all the more ardor your beneficent work. It seems probable that your Association, however, starts out under auspices if anything more favorable than those which greeted the advent of the Minnesota Society. The immediate vicinity of Winnipeg is not, I take it, so much an undeveloped country as was the region about St. Paul and Minneapolis in 1866 , neither city at that time being much in excess of 5,000 population. The purpose and work of horticultural societies in the west, too, are much better understood and more highly appreciated. They draw to themselves naturally an element that represents a very high type of morality and good citizenship. We have a right to be proud of the personnel of the horticultural societies. The work they do is an unselfish one, and deals with nature in her most attractive forms, and unless the springs of life are poisoned somewhere at their sources, yield to both the worker and the onlooker only the happiest results.

The members of the Minnesota Society expect to hear of large fruition in connection with the work of your newly formed Association, and we most heartily bid you God speed.

Yours fraternally,

$$
\text { A. W. LATHAM, }
$$

Sec'y Minn. State Hort. Soc'y.

\section{DISCUSSION.}

Mr. WHELLAMS. It seems to me that we might do the Society a great deal of good by associating with the sister society of Minnesota and gathering experience from them that will benefit us much. The reason I think that we should in some way endeavor to affiliate with them is that the conditions in which their fruit, etc., is grown, are 
about the same as those under which we ourselves grow them. As Canadians we want to be loyal and not go back on our own country, but we can do more good to our Society and ourselves by getting the benefit of their experience, and I think we ought to affiliate with the Minnesota Society if we can.

MR. WAUGH. I an pretty familiar, with some of the fruit growers in Southern Minnesota. They are very successful men and have spent a lot of time and work to good purpose. One inan was authorized by the State to spend $\$ 1000$ to aid experiments in growing apples. I think he went out at elbows at 120 different points but he produced the apples. Now their climate is not at all like ours. We think their experience is exactly what we want, but their experience must be taken with a certain degree of reservation though they have been successful and $I$, for one, would have no objection to affiliation but would rather agree with the proposal.

Mr. A. P. STevenson. I am perfectly in accord with what has been said in regard to affiliation with the Minnesota Society in preference to any other organization outside of the Brandon Society. As to the societies in Ontario they have nothing whatever in common with us in regard to flowers and fruit especially. I consider it would be a loss of money to affiliate with Ontario. For the last eight or nine years I have been a member of the Minnesota Society. There is a great deal in what Mr. Waugh says and while in Southern Minnesota, apples, grapes and other things do we11, in Northern Minnesota they do not have such good success. While there are a great many things we can get advantage of by affiliating with the Minnesota Society we should be careful and not accept everything as if we could reproduce the like here.

Moved by Mr. Whellams, seconded by Mr. Waugh, that this Society affiliate with the Minnesota Horticultural Society on the terms proposed by Mr. Latham, it being understood that anyone who is now a member of the Manitoba Horticultural Society may be received as a member of the Minnesota Society on payment of an additional fifty cents per annum.*

MR. BEDFORD. It would be well to present our views to the Brandon Society as regards steps to affiliation with them and get their views on this proposition.

*On further correspondence with Mr. Latham it appeared that his letter had been misunderstood, and that in accordance with the constitution of the Minnesota Society the Manitoba Society could not be admitted to affliation with the Minnesota Society, except on payment of fifty cents for every one of its members. The Executive Committee theiefore gave up the idea of affliation with the Minnesota Society, and resolved to be content with a policy of friendly co-operation. 
Prof. BAIRD. We must work with the utmost cordiality with the Brandon Society. It seems to me that the co-operation might take some such form as this. Possibly we might ask them to contribute papers to our annual publication. Then in addition to this, membership in their society should entitle each member to a free copy of this publication which we hope to distribute shortly to our own nembers; but it is for the Society to take action.

Mr. WherLAms. I move that we request the Executive of this Society to try and arrange to work with Brandon Society. Seconded by Mr. A. P. Stevenson and carried.

Mr. A. P. Stenenson. Let me say that there are two or three Horticultural Societies in Minnesota and different parts of Iowa, in the N.E., N.W., S.E. and S.W., but one, by becoming a member of one of these local societies also becomes a member of the State Horticultural Society. I have an idea that in time we may have a number of small societies, and by becoming a member of one of these anyone can become a member of the Provincial Society.

Mr. A. McKay. I would like to see the name of the Society changed so as to take in the whole of the North-West Territories. We would not like to affiliate with you, but we would like you to affiliate with us. If you change the name and we get up any society in the North West, let it be understood that the members of it would be members of the society here. I am sure in the North West we require such a society almost as much and probably more than you do here. I move that we remit to the Executive Committee the question of changing the name from the "Manitoba Horticultural Society" to some other that will give equal prominence to the North West Territories. This was seconded by Mr. R. Alston and agreed.

Mr. TOMALIN. Is it the intention of the Society to hold more than one meeting a year?

PROF. BAIRD. There has been nothing decided about the number of meetings.

Mr. Tomalin. I think we should make some arrangement for holding a Horticultural society show some time in August or about that time. I would leave it with the Executive to see what they can do.

Mr. WAUGH. I second that motion. I think the thing is a very feasible proposition. Carried.

Mr. G. McGregor. Do you confine the Society and its show to fruits and flowers?

Answer. No, we take in vegetables so as to make it a sort of general fall show of horticultural products. 


\section{Doubtful Fruits.}

\section{BY A. P. STEVENSON.}

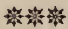

This is the first time I have had the pleasure of appearing before you at any of your meetings, and at the invitation of your honored presiding officer, I esteem it a pleasure to contribute my mite to the interest of your meeting by relating some of my experience in growing fruit in our Province.

I have thought it might be interesting to review briefly some of my experience in attempts to grow the larger fruits such as apples, etc., for after all it is around this class of fruit that centres the most interest. Good paying crops of small fruits can be grown here without much trouble, but apples, ah! that is another question; have we not all learned from dear bought experience that they are a failure here. Apple growing in the North-West is yet an unsolved problem.

I bought the first apple trees I ever planted in Manitoba in the fall of 1874. They were planted that fall in a garden here in Winnipeg; in the spring of $1875 \mathrm{my}$ trees were sound asleep and they are sleeping yet. Soon after starting on my farm at Pembina Mountain I bought another lot of standard apple, cherry, and plum trees of all the standard eastern varieties. They were a fine looking lot of trees; all lived and made a fine growth the first summer; the following spring not a living tree was left to mark the spot where they stood; what prevented me from surrendering to the hard winters I cannot tell, unless it was the endless amount of energy and perseverance it takes to make a fruit crank of a man. In 1880 I planted a number of crab apple trees; the most of them are with us yet and are healthy and apparently sound; they came into bearing the third year after planting and have continued to do so ever since.

In 1885 were planted one year old trees of Duchess, Wealthy, and Whitney; more trees were planted up to 1890 . 
During that year a large number of Eastern European or hardy Russian varieties were planted till over five hundred trees of ninety different varieties were growing with various degrees of promise, the larger number being one and two year old trees; surely now, I thought, out of all these varieties some will possess the necessary hardiness to stand our trying climate. The first tree to carry fruit was a variety named Blushed Calville; this is a summer variety, the best specimens measuring $10 \mathrm{~T} / 2$ inches in circumference and of fine dessert quality, color pale yellow, no blush.

The following year Lieby, Anisette, Wealthy, Little Hat, Silken Leaf, Ostrekoff and Simbrisk No. 1, all carried fine specimens of fruit. Last spring ten varieties were more or less covered with bloom, but a late frost on May 23rd blasted all hopes of much fruit. The above is a summary of my experience with the large or Standard variety of apples.

\section{CRAB APPLES.}

In reviewing briefly my experience with crab apples the prospects of success brightens considerably. I look upon the growing of this fruit with us as being beyond the trial stage. Our crop in 1896 was seven barrels, one tree alone yielding over one barrel. In size, appearance, and quality the fruit was far superior to any of the Eastern grown varieties offered on the market here. Thirteen different varieties have been grown here, a few have gone to the brush pile; of those left the most hardy and prolific bearers are Transcendent, Hyslop, Sweet Russett, Virginia, General Grant, and Whitney. The latter is a Hybrid and is sometimes classed as a small apple.

\section{PLUMS.}

We early made a failure of trying to grow the large Blue of the Eastern Provinces up here. The Russian Plums planted in 1890 promised better; six of the so called hardiest varieties were tried, but in three years they were all on the brush pile. 
The Improved Native Plums were more successful. Seven years ago seven varieties were planted, the first to reach the bearing stage was a variety named Cheney, followed closely by the Rockford, Wyant and Bixby. These are named in order of merit. For the quantity and quality of its wild plums along the foot of the Pembina Mountains has perhaps no equal in the Province, but among them all none are equal to the varieties named in size and quality. By selecting the best from our native thickets, given good cultivation and attention they will in a short time equal any of the so called Improved Native Plums, but they will then have become themselves Improved Natives. Authorities in the South claim that this class of fruit is superior in quality to the Prunus Domestica family.

\section{CHERRIES.}

The early Richmond were the first cherry trees planted. This is the variety that grows so abundantly in the Eastern Provinces. It is a total failure with us unless you grow it on what I call the Swivel Sytem, which is described somewhat as follows :-

Get one year old trees, plant in spring if season is favorable, a long slender shoot of a growth three to four feet high will be made, on approach of cold weather bend over close to the ground and hold there by pegs driven into the ground, cover lightly with earth. In spring remove the earth permitting the stem to lie prostrate, when growth begins to start turn up the extreme top and tie to a stake, keep off all shoots from the prostrate stem and encourage upward growth of the erect portion.

In the fall before the groind freezes cut the tree loose from the stake and press it down to the earth to the right or left and cover as before; the spring of the stem will permit the laying down of the trees with very little pressure; the prostrate stem will soon take root if left in contact with the earth, and to avoid this place stones or a piece of board under it. 
Our oldest trees grown on this plan have been nine years planted, the diameter of the prostrate trunks averaging about four inches. The first full crop was taken off two years ago; there was promise of a fine crop last year but the late frost blasted our expectations.

It takes five minutes to lay a tree down in the fall and the same time in the spring to raise it up again and tie to a stake.

A Russian variety named Shubianca $6^{\mathrm{m}}$ of the Bush Morello family is apparently hardy enough without any protection. It appears to be rather a shy bearer, having given only as yet a few specimens of fruit; the same will apply to the Ostheim and Bessarabian varieties.

\section{GRAPES.}

Eight years ago I planted my first grape vines; the varieties were Moore's Early, and Wyoming red. The latter was dead, root and branch, the following spring. Moore's early, on the other hand, has grown vigorously and carried over one hundred fine bunches of fruit in 1896. About half of these bunches ripened fairly well; the balance failed to ripen, although it is but fair to state that the location in which they were grown was too much shaded to encourage early ripening; had the vines been trained on a southern wall a larger percentage of the fruit would have matured. I don't think it is advisable to plant any variety of grapes with later ripening qualities than Moore's early. If an earlier ripening variety can be got, give it the preference. None of the other four varieties have carried any fruit yet, so their merits cannot be discussed.

This brings us to the end of the list of fruits that we consider as being unsuited and impossible to grow here with any great degree of success.

It will be readily seen from the above that I have hit little and missed much, and even that little will be missed unless certain conditions are complied with. The first is a favorable location, without which I am confident that even the smallest amount of success will not reward our efforts. A 
northern exposure is best, the ground sloping to the North if possible; a clay loam is best, and a sand or gravelly subsoil the worst, but shelter is needed and that from every direction. To plant trees on the open prairie with nothing to break the force of the wind or hold the snow in winter is only time and means wasted, and the expectations of the planter will never be realized. The trunks of the tree will also be greatly benefited by protection. This is best done by boxing the trunk with boards reaching from the ground up to the lower limbs, then filling in with earth. This keeps the body of the tree always in a healthy condition and lessens its liability of becoming black-hearted; of course the boards are removed in spring. Bark-bursting is generally more noticeable the first and second years after planting, especially if a vigorous growth has been made the past season; examine the trunk carefully, close to the ground and under the ground, and if you find the bark burst away from the wood wrap it tight around with a strip of waxed cotton then bank up with earth to exclude the air. Root-killing arises from young trees being grafted on tender roots and planting too shallow in our warm, deep soil; our dry winters and extreme freezing kill the tender roots and your tree dies. The danger is greatly increased if during the winter the snowfall is light or the snow is blown clean from around the trees. In 1893 from this cause alone I lost over two hundred apple trees; they all budded out nicely, showing that the tops were hardy enough, but they never got any further. On examination the roots were found killed on all trees around which no snow had lain. The best remedy for this trouble is to plant deep, so that the scion will emit roots, then plant the spaces between the trees with small fruits.

I believe in close planting; twelve feet apart each way is far enough and lean the trees to the south-west, head two feet from the ground. Never let your tree lean to the northeast, which it will have a natural tendency, to do, or the blazing sun in March will get in its deadly work.

Plums are supposed to succeed best when a number of varieties are planted together, but six feet apart each way is 
close enough. Train to a single stem at least two feet before heading; you will in this way overcome the difficulty often met with of the limbs giving way at the crotches, - this trouble is often met with. I find a wire nail driven through the centre of the crotch helps over the difficulty.

Now a word about seedling plums-perhaps I am somewhat prejudiced against them but briefly let me give you my experience with them. A friend gave me a dozen seedlings which he said were from an extra fine wild plum. They all grew and flourished and for five years I hoed around them and gave them every care and attention; in their sixth year they came into bearing. I let the fruit ripen, and well, vile! was no name for it. I let them go for another year but saw no improvement, then after a hard day's grubbing they were got rid of.

Three years ago some Weaver seedlings were planted. they carried some specimens of fruit last year, and judging from its quality some more grubbing will be the order of the day. These are my reasons for being shy of plum seedlings, they are an unknown quantity. Budding, grafting, or piece roots are the only methods known of getting trees true to the original. Only by wise selection can our native plums be improved.

\section{GRAPES.}

In planting grape vines the holes are dug about two feet deep ; as the vines grow the earth is filled till the surface is reached; this is to have the roots safe from the frost. The vines are laid down and covered with earth shortly before winter sets in, and later on covered with straw ; very little pruning is done and that in the fall previous to laying down. The canes in early summer are sometimes girdled, this hastening the ripening of the fruit from 8 to 10 days. Of course this can only be done to a limited extent as the canes thus girdled die the following year.

The above is a brief rambling outline of my experience in trying to grow the larger fruits in Manitoba. Roughly 
summed up the results are somewhat as follows: no large sized apple has yet appeared that can be safely recommended for general planting, that fair success can be had with certain varieties of crab apples grown in favorable localities, and that only by wise selection our native plum can be greatly improved. That grapes require winter protection, and that they must be of an early ripening variety, and trained on a wall with a southern exposure.

Mr. Stevenson then goes on to say that thousands of dollars go annually out of the country for fruit stock that is only useless trash here. I say beware of the man who sells wonderful new things at extravagant prices. In spring he works the ambitious novice who is anxious to get some of the novelties before his neighbor has thought of it, for instance tree raspberries and strawberries, with great names and great expectations. In the fall he may be seen unfolding his lovely colored plates to some solitary farmer whose mouth is watering for the luscious fruits of his early days in the Eastern Provinces ; somebody is quoted as saying so and so. After a season the world gets tired of its old truths and hungering and thirsting for a good lie will swallow anything.

I wonder if that is the reason people take so kindly to a canvasser of unheard of horticultural novelties. The far fetched and dear bought theory is the biggest humbug in the world when applied to trees.

Might I suggest that there is a capital opportunity presented here to our Society to step in and do their best to lessen this evil.

\section{DISCUSSION.}

Question. What size should the boxes for tree protection be?

Mr. A. P. STEVENSON. 4 inches square inside would be plenty for two year old trees.

Question. How high should they be?

Mr. A. P. Stenenson. Just to where the branches start. The rabbits are very destructive, and I find it advisable to train on a single ste:n instead. 
Mr. BEDFORD. Are these imported plums early enough to escape the frost in the fall? And how is the Cheney in that respect with you ?

Mr. A. P. Stenenson. The Cheney is one of the very earliest plums we have.

Mr. BEDFORD. Every year the fruit of the De Sota has been injured by early frost at the Brandon farm. The Rockwood, the Weaver and others are too late. The Cheney is one of the earliest.

When Professor Saunders and I visited Mr. Stevenson's farm we found everything in good condition. Mr. Stevenson knew the name of everything on the place. He has a good plan of keeping account of all he has. He knows where each tree is, when it was planted and all about it and the same with everything else.

Mr. Stevenson was asked what he did to get rid of the Aphis, and he said in reply, that he had never given the Aphis much attention.

MR. BEDFORD. Have you tried tobacco for it? We have been very successful with it at Brandon. We take about twenty-five pounds of waste tobacco from the cigar factories, soak it and spray the trees with the juice, and that has been our best remedy for the Aphis on the plum trees.

Mr. D. D. England. I found the difficulty to be that the Aphis were under the leaf and spraying did very little good. The most satisfactory way was burning some tobacco stems in a pan under the tree. We put a canvas over the tree to keep the smoke in and this killed every one as far as we could see. That was the only plan with which we had success. I never tried spraying.

MR. WHELLAMS. I think this is a very important point as this insect is very injurious to fruit. I tried kerosene emulsion, even making three applications with very little effect, even though the mixture was strong enough to damage the leaves. I am glad to hear of something as satisfactory as Mr. Bedford gives. I think this Aphis does more harn to fruit bushes than any other insect we have.

Prof. Barrd. I agree with Mr. Whellams. Emulsion injures the trees. I applied it to the under side of the leaves thoroughly. I used it too strong in one case and hurt the leaves and yet the Aphis seemed to flourish.

MR. BEDFORD. In British Columbia they use this tobacco application very largely and find it very successful. I have used it and find it far more successful than anything else that I have tried.

Mr. D. D. ENGLAND. I have tried it too. It does not matter how strong you put it on, it does not injure the leaves, but sometimes it injures the roots.

Mr. MCKAY. I may say that you can grow tobacco with less expense than you can buy it and it does as much good. 


\section{Trees and Windbreaks,}

BY ANGUS MACKAY.

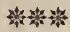

There is no subject to-day deserving more and receiving less attention from the settlers in the Territories, than the cultivation of trees and windbreaks. Whatever success may have been attained in many districts with cereals and stock, tree-culture may be truthfully said to have not as yet had a beginning. On our great treeless plains many districts have been settled for ten or fifteen years, but no effort has been made to beautify the homes, protect the fields or buildings, or provide fuel for future years.

While for some years farmers throughout the country have no doubt had difficulties to overcome, many are now in a position to devote some time to that which will not only afford shelter but will be a safe investment for all time to come.

Tree, like cereal culture in the Northwest, requires thought, attention and patience before success can be attained. Thought as to what to grow; attention to planting and cultivation, and patience while the trees are growing.

The great lone land is not favored' with a superabundance of moisture, and this want must in some way be overcome or trees cannot thrive.

Many theories have been advanced as to why the plains are treeless. Some maintain that prairie fires are the sole cause; others that prairie fires and hot winds are to blame, and others that severe winters and springs, together with unsuitable soil are against the growth of trees. While all these have, no doubt, had great influence over tree life, I think not any one, or all together, may be said to have been the true cause of the barren state of our plains. Want of stufficient moisture has been and will continue to be fatal to 
tree life in this conntry, unless cultivation assists nature in overcoming the deficiency.

Prairie fires have, no doubt, done great harm in the past, but they are powerless against cultivation. Hot and cold winds are, however, very injurious to trees in spite of the best cultivation, and while severe winters and backward springs doon many varieties of trees they are not fatal to all.

The want of sufficient moisture may, to a very considerable extent, be overcome by proper cultivation, and although the best cultivation together with all the rain Providence sends the Northwest, cannot be sufficient for the proper development of trees, the results will be very gratifying.

The first step toward success in growing trees is the thorough cultivation of the soil the year previous to planting, for while hundreds of trees die from want of cultivation after planting, thousands die from want of it before.

As is now generally known, harrowing the land stores up a large amount of moisture. This moisture is then available for plant life, so long as the soil is kept in fallow condition; that is solong as its surface is stirred a few inches deep several times during the season, and weeds or other surface growth not allowed to absorb the moisture.

If the soil is in this state when trees are planted there is little danger of loss from want of moisture, and if the trees are in proper condition when planted no loss whatever need occur. Their life afterwards depends on cultivation for a few years. Deep cultivation before and shallow after are essential to success; want of either means certain failure.

Several varieties of trees stand out prominently at present by reason of their adaptability to the Northwest, viz: Box-elder (Acer Negundo), Russian Poplar (Populus Bereolensis), Russian Poplar (Populus Wobstii Riga) and American Cottonwood (Populus Monilifera). While these may prove to be short-lived varieties, and in after years be thought very little of, at present we have found nothing better to make a start. American Cottonwood is without doubt the 
most rapid growing tree in the Canadian Northwest, and while in leaf is a very beautiful one.

The Russian Poplars mentioned are two very hardy varieties, fast growers and fine looking trees, when room is given them for development.

Box-elder is probably the most valuable of our fast growing varieties, and is certainly the most commonly grown on account of its adaptability to the climate and soil, easy germination, and the large quantity of seed produced. Box-elder is also a valuable tree for the purposes of protection.

The Native Ash (Fraxinus Americana), Native Elm (Ulmus Americana), and Native Birch (Betula Alba) are good trees for forest cultivation, but are not as suitable for hedges or windbreaks as the varieties previously referred to. However, in all probability they will be found more valuable for fuel or other useful purposes than either Box-elder, Poplar or Cottonwood.

Whether our plains can ever be covered with sufficient forest to influence moisture is questionable, but there is no doubt as to our ability to protect our farms from the winds which are the cause of an immense amount of loss each year. We can overcome drought to a considerable extent by cultivation, but without protection from winds a great deal of the good effects is lost.

Windbreaks, to be effectual for fields or grain crops, require to have height ; for buildings, height and compactness ; for gardens, compactness, and for lawns, beauty.

For fields, a mixture of Cottonwood and Box-elder makes a good hedge; the Cottonwood to attain height, and the Box-elder to give bottom compactness. Box-elder alone gives good results, but does not grow high enough to protect latge fields. A single row is preferable to a number of rows, being more easily cultivated, and taking less room, at the same time answering the purpose in every respect. 
For around buildings Box-elder and the Russian Willow (Salix Varonest) are suitable. Both are easily grown and afford effectual protection. The willow makes the more compact hedge, and whether in leaf or not is attractive in appearance.

For small enclosures or for protection of gardens or fruit plantations Southernwood (Artemisia Abrótanum) has given excellent results and is equally effective in winter, spring or summer. Any variety of hedge answers the purpose when in leaf. . Southernwood in leaf or not affords ample protection.

The Russian Willow has also been found to be a good hedge for gardens and is next to. Southernwood for protection all the year round, besides being a handsome hedge which cannot at all times be said of Southernwood.

For lawns or places where low hedges are desirable the Native Snowberry (Sympharicarpos racemosus) makes a pretty and easily kept hedge. Side roots are troublesome after a few years, but are easily kept in check by cutting along both sides of hedge once a year. This plant when kept in order has much the appearance of box and is green from early spring till winter sets in.

Ginnalian Maple (Acer Ginnala) makes a most beautiful hedge as do also Lilac, Tartarian Honeysuckle and Siberian Pea, all of which are hardy, easily grown and easily kept in order.

Since the commencement of operations on the experimental farm, considerable attention has been given to forest cultivation, and at present we have plots from one-tenth acre to five acres in size, in all stages and conditions.

The first plantation started was box-elder, sown in rows. The trees are now fourteen feet high and they have received no attention since 1890 and very little before. The seed was sown too thick, so it is a case of "survival of the fittest." Other plots have also been sown and left after two years attention and are now at various stages of height. Plots have 
been planted with trees set out at a distance of $2 x / 2,3,3 \frac{x}{2}, 4$, 5,6 and 7 feet apart. Some plots are all box-elder, others all ash and others all elm. Then there are plots with box-elder and ash in alternate rows, box-elder and elm, etc.

In the transplanted plots the trees set out $2 \mathrm{x} / 2$ and 3 feet apart, cover the ground in the least time and require less cultivation than those set out at greater distances apart. Besides this the trees attain height more quickly and are more suitable for transplanting, and no doubt as they develop will make better trees for any purpose.

Trees, at a greater distance than three feet, have a tendency to throw out branches from the body, and expend their strength in breadth insteed of height. This is especially true of Box-elder and Elm.

Plantations of box-elder and ash, 1 tree of the former to 2 or 3 of the latter, do much better than all box-elder or all ash. With "all ash" plantations there is not sufficient ground protection from the sun early in the season and with Box-elder there is too much. Both together afford sufficient protection, and at the same time permit light and air to enter. For the same reason Box-elder and Elm, in the proportion mentioned, do better than all Elm.

Native Ash (Fraxinus Americana) is, I think, the most valuable tree we have for forest cultivation. Although slow of growth for a few years it takes a smaller amount of moisture and less cultivation, and will, no doubt, live in our dry climate many years longer than Box-elder, Poplar or Cottonwood, and at the same time be more useful for fuel or other commercial purposes. 


\section{The Winter Protection of Plants.}

BY A. B. BAIRD.

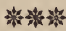

The Horticultural Society, I venture to think, can scarce1y render a better service to its members and the public generally, than to make public what is known already about the classes of plants that can with a little care be carried through our Manitoba winter, and if possible extend the range of plants capable of being cultivated here by studying how plants with which we have hitherto not been successful, may by the adoption of improved methods be assisted to withstand the rigors of our severest seasons. This is a subject upon which we can get little help from our friends to the South, the East and the West of us, and we are therefore left to work out our own destiny and discover what plants will live in a state of nature with us and what by the exercise of a few artificial precautions can be helped through the winter.

My own three or four years of experimenting, of which I have only recently begun to keep any memorandum, will throw only very little light on the subject, for the conditions of success are so numerous and so complex that one is obliged to verify his tentative conclusions through a series of years before we can announce them with confidence. What I have to offer is therefore only a single contribution towards a body of knowledge which will only be arrived at after we have all observed and experimented and reported for a few years. And there is abundant encouragement for us to go on in this line. Who in Manitoba would have believed half a dozen years ago that hybrid perpetual roses can with safety be wintered out of doors with us? And yet this is one of the conclusions which I think I may venture to say is now pretty well established. Who among us would not have laughed a few years ago at the enthusiast who first risked his tulip bulbs by putting them into the ground in October, but it has been done 
time and again with such success that it does not require a prophet to say that soon tulip bulbs will be planted by the thousand every autumn in Winnipeg and throughout the West.

Allow me to call attention to some general considerations which are of importance before going on to note the methods to be employed in the case of each species.

It is very desirable in the case of a half hardy or tender plant that it should be prepared so as to enter the winter in as good a condition as possible. In other words the woody part of the plant should be ripened as well as possible. Let the growth be as rank as you like in the spring and early summer but do not by abundant watering or by the use of manures encourage a strong growth in the late part of the summer. The pinching back of raspberry canes is usually to make the plant branch out and so bear more fruit, but it is good for this purpose too that it hinders growth late in the season, so the cutting back of roses will prepare the bushes for going into winter quarters in a much more satisfactory condition.

Again, of the conditions of success in winter protection one is to have a substantial covering over the plant so that the alternate freezing and thawing of spring days and nights will not injure it; and the other is not to have this covering so close as to smother the plant. Leaves, which are so often recommended in eastern horticultural journals, are unsatisfactory because (not to speak of being hard to get) they are so liable to blow off and leave the plant exposed. Strawy manure is liable to the same objection in windy situations and when there is nothing else to be used, as in the case of strawberry beds, it is well to add a few branches of trees which not only keep the straw from blowing about but they have the additional merit of holding the snow.

To obviate the smothering of the plants the best method in my experience is to cover the plants with inverted sods 
laid in such a way that there are some air passages underneath and among them. If this is done in a neighborhood infested with mice it will be necessary to guard against their depredations by scattering some handfuls of poisoned wheat about the mounds.

It is also very desirable to have the wintering plant kept somewhat dry. Nothing is more certainly fatal to it than that it should stand in a foot of water for a while in the early spring. And it is good policy in the case of the more tender plants to cover the mounds with tar paper or with packing cases to keep off the wet.

Now to speak more in detail about the course to be pursued with regard to various kinds of plants it is to be noted that some require no winter protection at all. Small fruits like currants, Downing gooseberries, Turner and Philadelphia raspberries, do quite well without any winter protection, although in the case of raspberries it is altogether better to cover them because it brings them through the winter with unimpaired vigor and because if they are branchy, as they ought to be, the melting snow is very liable to break off the branches.

Many of the perennial flowers like the delphinitums, emerocallis, perennial phlox and sweet william do quite well in an ordinarily sheltered situation without any protection but it is safer to scatter a little litter over them ; and there is also a long list of flowering shrubs which are quite independent of any artificial covering during the severest winter and the most unevenly regulated spring.

There are on the other hand some plants ordinarily reported hardy which have not proved to be so in my experience. I have tried twice to bring hollyhocks through the winter out of doors and have not succeeded, although the Indian Head experimental farm reports that it succeeded in 1894. My efforts to winter hydrangea paniculata successfully have been disappointing but on this line I have not given . up trying. 
But between these two extremes of plants that need no protection and plants that cannot be protected there is a large class that will richly repay a little care.

The best way to protect raspberries has been often described, but possibly there are some here for whose benefit it may be repeated. After the old canes and all but five or six of the new ones have been cleaned out, take out with a digging fork a little earth from one side of the roots, then loosening the roots on the other side also a little with the fork, bend the canes gently over till the tips reach the ground, take care to do the bending as much as possible in the roots so that the canes need not be bent sharply over and broken. Have a boy to hold down the canes while you place a few shovelfuls of earth on them to hold them in position. Even for the tender or half hardy kinds like Golden Queen and Cuthbert it is not necessary to cover the whole plant with soil. All that is needed is to cover it partially so that it will get the protection of the snow during the winter. The work is very easily and quickly done, a man and a boy can lay down snugly a long row in a very short time and it is a great pity to run the risk of losing a part or the whole of the next season's crop for want of a few hours' work.

For roses the plan is very much the same only that more pains are taken. The ground about the root is loosened sufficiently far down to make it possible to lay the plant over on its side, then it is covered with inverted sods laid in somewhat open order and the whole is covered with a piece of tar paper to keep out the rain. By this means even tender roses can be kept safely through the winter. It proved successful last winter in my garden with the hybrid perpetuals: Duke of Edinburgh, Alfred Colomb, Mrs. John Laing, General Jacqueminot and Paul Neyron, the climber Crimson Rambler, the moss roses Glory of Mosses and Henry Martin and the Lord Penzance Sweet Briars, Amy Robsart and Anna of Grierstein. Those which succumbed were the hybrid perpetuals: Gloire -Lyonnaim, Black Prince and Dinsmore, and the climber Mary Washington, probably from being covered too closely. But 
perhaps last winter with its early and abundant snowfall should not be quoted as an average winter, especially when we know on good authority that the tea rose Madame Caroline Testout survived the winter in Fort Rouge without any protection whatever. There are many roses no doubt which will live through our winters without being covered at all. Roses of the Rugosa class need no care. The yellow roses Persian Yellow and Harrison's Yellow are perfectly hardy. My friend, Professor Hart, has had for a number of years in his garden a moss rose, a yellow rose (probably Harrison's yellow) and a small pink rose which have lived and bloomed year after year without protection, although they are often frozen back considerably. The garden is tolerably well protected by the house on the North, a board fence on the South and West and by trees.

The proper time in the autumn to begin to protect plants is when the frost begins to stiffen the ground, usually in the first week of November, and the covering ought not to be taken off until the plants are about to start into life. The mistake is very often made of uncovering too early. Indeed if by leaving the covering on, the beginning of growth in strawberries or raspberries can be delayed for a week the plants will have escaped very likely one of their worst enemies, - the danger of frost while they are in bloom.

The fruit grower and the flower grower in Manitoba have to face and to conquer difficulties which do not beset the cultivators in milder climates. But what of that? Difficulties exist only for the purpose of being overcome. Anybody can grow flowers in California or British Columbia : it is only the man of intelligence, of perseverance and of watchfulness who can succeed under conditions which are as new and some of which are untoward as ours.

\section{DISCUSSION.}

Some one asked about the hardiness of the Hydrangea. Mr. Bedford spoke of one variety as being very tender with them at Brandon. He said, "We got plants from Rochester and Ontario and both were 
tender. One day while visiting the greenhouse I was told that they had sone of these plants that came from St. Paul and they found them hardy. I bought four or five of these plants and they have proved to be hardy and they bloom every year. They bloom very late in the season, so I think success depends largely on where you procure seeds or plants. Fron the East we found the elm tender, while from Oak Lake we found it hardy, and so we should be very careful about where we procure them. Get them as far north as possible.

Mr. A. McKay. I would like to ask the best time for uncovering plants. The greatest danger to perennials is taking the covering off too late in the spring. When we cover them with manure and straw until the danger of frost is over, even a cold wind will kill the leaves. This last two or three years we have stopped mulching and we have found that these perennials will stand much more frost. My experience has been that if we could cover them to keep them back by keeping them in a cold state by ice or snow that they would be all all right, but if we have just a small mulch on the plant, it begins to grow and a light frost or wind will kill it.

PROF. BAIRD. My experience quite coincides with Mr. McKay's in that respect. With the exception of Raspberries I have given up the plan of mulching. With Raspberries I put down all kinds. I pinch them back during the summer to get the vines very branchy before the fall. Then I lay them down about the beginning of November for the purpose of protection, so that the branches will not be broken off them when the snow melts in the spring, even though they do not need it to keep them from being winter-killed. One finds that in this case, as in too may others, it is a bad plan to tamper with nature any more than is absolutely necessary, so with my pansies, for instance, I do not cover them at all. Sometimes a few of them die, but the majority of theil come through very well. As regards Phlox, Sweet Williain, etc., iny garden has a fence near by and the snow lies pretty late in the spring and I leave them to the tender mercies nf nature. With roses I find the difficulty to be in interfering with the roots, but get over this by pinning the plant down and covering very lightly.

Mr. A. P. Stenenson. It is sometimes suggested as a protection for tender roses that railroad ashes are as good a thing as can be got. My experience with the plan of covering with sods was not very pleasant. The mice would get in and bark the bushes. But as regards what Mr. Bedford said of getting the trees from as far north as possi. ble I may say that we have one very good illustration of that at home. A number of years ago we got twenty-five of the Ontario soft maple trees and some from northerly Wisconsin at the same time. Those from Wisconsin are probably eighteen feet high, while those from Ontario are probably eighteen inches high; they are killed back every winter. 
Prof. BAIRD. In answer to Mr. Braxton, I may say that I have only about eighteen or twenty roses and the number is not so great but that I can take a great deal of care of them. I do not disturb the soil any more than is required in pinning them down, but a friend of mine here in the dry goods business has a method which does not require pinning at all. He covers the roses over with packing cases filled with straw or manure, and leaves thein standing, and in that way they are protected from the snow in the spring and from changes of temparature. His method seems to be pretty good.

$M_{R}$. MCKAy. We have a lot of boxes that we use in growing our melons and things that we wish to ripen early. These we put over the roses in winter filled with leaves. In regard to laying down raspberries we have none that will stand without protection in the NorthWest. We have to put them down every year, but we never touch the roots. We find that we have to cover the whole bush, as unless we do, it will not bear fruit although it may look all right. If we had snow it might not be so, but we have no snow and so find protection of the whole body necessary.

Mr. Tomalin. In the case of the Turner Raspberry, did backpinching make it branch out ?

\section{Prof. BaIrd. Not as freely as the Golden Queen and Cuthbert.}

Mr. Tomalin. That might do very well in the city where you have only a small garden, but in growing fruit for sale a man cannot lay them down as he has not time. I have laid them down and I have left them standing and $I$ fail to see any difference. We should get a kind that will stand. For a number of years I have grown raspberries and I would advise anyone growing them in the country not to cover them. The way I would grow them, if convenient, would be to have them 20 to 25 feet apart and have strawberries between so that the raspberry bushes would hold the snow to cover the strawberries, as about four feet of snow is the best covering you can get for them.

Mr. A. P. STFVENSON. I have tried pinching back alternate rows and certainly I failed to see a particle of difference in the crop. In reading the report of the experimental farm I notice that they had no favorable results from pinching. As regards what has been said about covering strawberries, I find that if I do not mulch them the frost in spring is liable to spoil the blossoms. Last year one half of my crop was ruined by leaving the plants uncovered. Those that we mulched were kept back and did very well.

Mr. MCKAy. We have a raspberry at Indian Head, the Dr. Ryder, It is the best raspberry we have ever had and next to the Turner in hardiness, and I would like to know if anyone here has heard of it. We got our first vine in 1889 from Boston. 
PROF. BAIRD. I confess that the Cuthbert aud Golden Queen seein to be so much better in quality than others, that we have paid attention almost exclusively to them. The trouble of laying them down is not so great as Mr. Tomalin fears. A man and a boy can lay down half an acre in a day.

Mr. Tomalin. There is another thing that I did not mention. In the country the snow blows off and if you are going to raise them for sale you must do something to save the moisture for them. The Turner and the Philadelphia are the only two that will stand without covering. These two have been hardy with us so far.

Mr. A. P. STEVenson. One of the promising varieties at Nelson is . called the Loudon. The only objection to the Turner is that it is too soft for a shipping berry. It is a fair size and good quality but for market it is too soft. The Loudon is hard and the fruit appears firm. I have not had it very long but I think it is a very desirable variety.

\section{The Importation of Fruit and Nursery Stock.}

BY R. R. SCOTT.

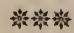

You are all aware that the fruit growers of Eastern Ontario have been asking the Government to stop the importation of nursery stock and also fruit on account of the San Jose Scale. That would be a very serious matter for Manitoba, and our Board of Trade took it up very strongly and we have been assured that nothing will be done until we are heard from. I wrote to an old shipper in Santa Clara, Cal., on the subject of the San Jose Scale and a short time ago received his answer. He has had about fifty years experience in growing and shipping fruit. You will know that he has considerable experience when I tell you that he is one of the oldest shippers in the United States. In one year his loss was $\$ 50,000$. He enclosed me a copy of a bill which has been brought forward in the United States to stop the importation 
of infected nursery stock, but it is too long to read so I will just leave it here for the Society's use. The substance of it is prohibiting infected nursery stock or poor fruit from coming in to the country, the Government officials to have the inspection. In regard to nursery stock, if the law proposed by the fruit growers of Eastern Canada were passed it would cause great hardship here. Our climate is very similar to that of Wisconsin and fruit trees from there would be more adaptable to Manitoba. I would advise planting nothing but the very best varieties of fruit; there is no use in wasting your time and money in putting down poor stock. Ontario people and Ontario shippers have an idea that anything is good enough for Manitoba, but we don't think so ; we want the very best that can be grown. We are a long distance from the markets and freight charges are high and it requires a considerable amount of money to handle it, so let them keep their poor stock at home. I think I have never seen poorer peaches than those coming from Ontario, although they are able to grow very good peaches. I do not think, from my experience, that Ontario peaches will carry. I have had friends come from the East and show me a sample of what were good peaches when they left home but they would be all spoiled. They cannot be brought in here at a profit. We want to enjoy some of the good fruits here as well as they do there, and if they stop the importation of peaches from the United States it would be a very great hardship to the country. And so with apples. Take the King, Tompkins and Gravenstein. These three always command a very high price in the Old Country markets, $25 \mathrm{~s}$. to $28 \mathrm{~s}$. per barre1, while such as Spys and Baldwins have only brought as much as 16s. You see the nice profit people have in growing these good fruits.

Now I will speak of the smaller fruits that we can grow nearer home. A gentleman at Stonewall grows quite a numof small fruits and often he drives up to the door and his goods look so nice that we buy them even when we do not want them. Take the small item of Rhubarb or Pieplant 
for instance. His always looked so nice that even when, we had no place to put it we have never yet made a loss on that good article. We have yet to make our first dollar in selling poor fruit and we have had sixteen years' experience. Mr. A. P. Stevenson spoke of having good success with Crab Apples. We find that the Transcendent and Siberian are good shippers. The Siberian is not as good as the Transcendent. He spoke of Moore's Early Grape. One of the earliest grapes we get from Ontario is Moore's Early. If you cannot grow Moore's. Early in this country you cannot grow the later varieties. Peaches are sold so cheap here, as low as two cents each or twenty-five cents a dozen, that it is hardly worth the time of going into peaches if you have to turn down the trees every year. Cherries are very expensive, in fact we have never attempted to bring them from Ontario, but get them from California, Oregon and Washington, and even they are expensive. We cannot afford to sell them for less than from $\$ 1.00$ to $\$ 1.25$ a box of 8 pounds.

I would like to have some fun at your rabbits, Mr. Stevenson. I would hire the work done of fixing the trees and I would shoot rabbits.

The impression I want to leave with you, gentlemen, is to get the very best nursery stock it is possible to get and grow the very best goods. You hear of the poor apples you get and then scold the poor storekeeper, but it is not his fault, nor is it the wholesale man's fault, nor the packer's. Large firms doing business pack from 10,000 to 20,000 barrels a year, and it is impossible for one man to supervise the packing of every barrel.

You will find a number of small apples in the centre of a barrel. Now it is not the storekeeper's fault, nor the packer's, it is the narrow-minded grower's. He is so small he would go inside a walnut shell and yet have rooms to rent. These apples do not pay the grower, the buyer or the packer. We have our own packer in the east, who has for a number of years bought from one of the very largest and wealthiest growers. That gentleman tells his packers, "Do not pack 
too close, and pack nothing but the very best. I can sell my seconds around home or get them made into cider," and as for us we make more money from what that man sells us than if we bought cheaper fruit. We pay him more for his fruit than we do his neighbor, and the man who handles them can make money out of them, and the man who sells them in the first place grows rich on them. You gentlemen that are going into the nursery business get the very best, whatever you get, even if it is only currant bushes, get the best.

\section{DISCUSSION.}

Mr. Tomalin. Did you ever try strawberries that are grown here. They are the very best in the world. The ones you bring in are very little good.

Mr. Scotr. We import from ten to forty cases daily during the strawberry season, but before the Manitoba berries are in the prices are down. The reason we cannot buy them is that we do not get a chance. There is no margin between the wholesale and retail prices. There is no profit for us, but if this gentleman will grow us from ten to twenty cases daily I will give him a good price for them. We have never been able to obtain them here in Winnipeg.

Mr. Tomal, People here always try to run them down. Two boxes of mine would make three of the imported ones, and yet they will give five cents more a box for the imported ones.

Mr. A. P. Stenenson. My experience is that the Manitoba berries are the best that we have ever got. I have never tasted berries with a better flavor. You will get a good profit for all you can grow.

MR. Gol,DEN. Berries grown here have a better flavor than the same variety grown in Ontario.

MR. BEDFORD. In the matter of rhubarb, I find that Tottle's Improved is a first class variety and is very productive. It has been very useful to us in the west, in fact better than anything we could get from the east. I think that must be the same variety that we get from Mr. Tottle of Stonewa11, but we did not know the name of it. Professor Saunders gave it its name. It is known now throughout the length and breadth of the 1and. I just mention this to show you how useful the wholesale man may be to the producer by pointing out the very best varieties of fruits to use. 


\section{Protection of Birds,}

BY REV. W. A. BURMAN.

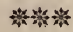

Mr. Chairman, ladies and gentlemen :- A few days ago I wrote to the chairman that it was impossible for me to prepare anything like an address on this subject. I have been out of town and have been pressed in many ways for time, but I may, perhaps, say a few words that will set some of you thinking.

The relation of birds to horticulture and agriculture is more or less understood by everybody. We are all familiar with the crow with his dark glossy coat, but perhaps the farmer is better acquainted with the blackbird. I am one of those, and I hope there are a great many here, that think the bird is always the friend of the agriculturist. There is only one bird that does not belong to the class, the English sparrow, which is not a particular friend of the agriculturist. When we consider birds in relation to the cultivation of the soil for flowers or in any other way, we want to note for a moment their place in nature. They have, of course, a very important place to fill between animals and fishes and are connected with those two great divisions in more ways than one, but we have to consider them to-day in relation to their habits and food. There are three divisions, the flesh-eating birds, called the carnivorous, the birds that eat grain, called the graminivorous, and the insect-eating birds called the insectivorous. Perhaps it would help us to look at those which feed on insects. Apart from any bearing on the subject, insects have a great deal to do with the ripening of fruits. Indirectly a large quantity of the fruits grown here depends on insects for the setting of their blossoms. The want of them may very seriously affect the setting and the ripening of our fruits. We cannot afford to leave out of consideration the effect of insect life. You will find that wherever the birds have been destroyed the insects are too numerous. Nature, if left alone, will keep the-balance. 
Carnivorous birds, such as hawks, owls and others have a very important part to play in nature. I have often marvelled at the denseness of many people in what we may call the gopher districts, and at the eagerness with which they will pursue their very best friend. As soon as a hawk appears some one is after him, either the farmer or his son, and they are not satisfied until he is caught and his wings set up as ornaments. I have observed that wherever we have a fair number of hawks and owls, gophers and mice are kept in check. I should like very much to see in some of the acts which regulate these matters that any person may be prosecnted for killing these. Even if the hawk does steal a chicken or two, he earns them, for we have often and often seen acres of land that would have been destroyed if it had not been for these birds.

I would like to mention here the badger as another great friend of the farmer although he is not a bird.

Then we have the insectivorous birds. Among these may be named the fly catcher, wren, chickadee and the black bird and others. These do a great deal of excellent work in spite of the bad character which they get and which they partly deserve. I was unable to put my hands upon some information I have somewhere about the result of an examination of the crops of a number of birds which had been killed, and the number of insects which they were found to contain was something immense, so that you see the number of insects which a good healthy bird, his wife and family will require is extremely great. Fly catchers live upon small insects generally. The wren and other small birds live largely upon the larvæ of insects and upon their eggs. Then there are others which keep in check the butterflies and other insects of that class. A curious thing is that certain birds eat certain butterflies and will drop any other kind they may happen to catch, and there are some butterflies that no bird will eat. A very large part of the work in killing insects is in looking up grubs that would eventually make butterflies. If you have watched the birds that follow the plow, you will 
have noticed them go along and pick out the wire-worms, etc., so that in this way.we see that they must be the friend of the farmer, and whatever bird or animal is the friend of the farmer is also the friend of the horticulturist. It is a pity that we have no protection for these birds. A large number are shot by those who have nothing better to do, and some, as you know, in different parts of the world, have been hunted out and destroyed for the sake of their plumage. I am glad that London society has taken up again the matter of wearing so many plumes in the hat. I am sure that the ladies are too fond of flowers to any longer suffer the cruelty, that is involved in securing the plumage, to be practised.

There is a third class, the Graminivorous. These are not always the friend of the farmer. The blackbird will eat grain as well as insects. We can tell this class often by the shape of their beak. The sparrow is one that will not eat insects. I remember a gentleman who was well posted in these things saying "Do not let anyone ever persuade you that the sparrow feeds on insects. You can tell by its beak that it is intended to eat grain." I have watched a large number of sparrows and I never saw them eating anything but grain. They will bear being watched. If any of you farmers having come from England are inclined to let them alone, I advise you to let sentiment go at once. They are just the one bird that we ought not to protect here. It is not long, four years or so, since I saw the first sparrow in the city and now they are very numerous and are scattered nearly all over the Province and in the summer you will hear more of them. You ought not to protect the sparrow. They are very destructive of other birds. They have a cruel way of insisting that they have a right to whatever they can get. They even steal the nests of other birds and lift the young birds over the side of the nest and let them drop to the ground. Then Mr. and Mrs. Sparrow will set up housekeeping in the nest they have obtained in this way. I am afraid that take him all round he is a very bad character. When the sparrow gets possession of a town as he will do in time, he will drive every other bird away and not only so but he 
will get up picnic parties in the grain season to the farms and come back at night, like other picnickers, very weary but very well satisfied.

I have just tried to give you some thoughts to set you thinking. I should have liked to have gone further into the subject and give something that would have been of value. We have a great number of lovely birds in the country but there is no doubt we have very much to do in the way of protecting and looking after our birds. There is just one aspect which we have not considered and that is that the presence of birds in our gardens makes them much more homelike and pleasant. It is a dreary place where you have no birds. I do not live in a very nice part of the city. Some of you are more fortunate and I would advise that you have them come about because of the education we gret in watching their movements and especially where there are children every effort should be made to induce them to come about.

We come once again back to the matter of gardens. Let us remember that the birds are given to us to help us in this matter both by their labors and song, so let us pay every respect to these little inhabitants. I am sorry I have not been able to make my remarks in a clearer manner but I hope they will set some of us thinking.

\section{DISCUSSION.}

MR. BEDFORD. What does the King Bird feed on ?

Mr. BURMAN. I think he feeds on everything. So far as I know a great many feed on grasshoppers. From all I have seen of his habits he seems to do so. Of course a good deal depends upon the locality.

MR. BEDFORD. The reason $I$ ask this is that they are somewhat troublesome to the bees.

Mr. BURMAN. I believe that they do feed on the bees, but you will notice that they take care that it is the drones they get at.

Swallows do not need much encouragement to come around. We have three kinds of swallows. The chimney swallow is seldom found in hollow trees. They build in chimneys, and I cannot say that I appreciate their attentions in that respect. They have a way of moving around at night which is unpleasantly suggestive of ghosts. 


\section{Forestry,}

BY E. F. STEPHENSON.

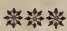

Mr. President and Gentlemen : I am much pleased at receiving your invitation to read a paper on "Forestry" at your annual meeting, and, while appreciating the compliment you have paid me, I feel there are some aspects of this important subject which could be more ably dealt with by other members of this Society. If, however, any effort of mine will conduce to awaken a wider interest in forestry and stimulate the public to a study of the subject and appreciation of its great importance, it will be another proof of the benefit arising out of this organization.

The government, fully recognizing their responsibility to the public, have taken the initiative in the protection of our forests; but while the general public remain indifferent to the subject and fail to appreciate its importance, any regulations which the government may make for the conservation and maintenance of the timber supply, must, in the nature of things, fail of its intention. It is to this aspect of the question, I suppose, that the efforts of the Society are to be directed.

It may not be out of place, however, to state briefly what has already been done by the government in the direction named. All lands valuable for timber are being reserved from sale and settlement; and where timber grows in heavy belts, such as in the Riding Mountains, the Turtle Mountains, the Moose Mountain and the belt of timber known as the "Spruce Wood," South of Carberry, permanent timber reserves have been established. The area comprised within the reserves selected is upwards of 1,500,000 acres. They are in charge of competent bush rangers, who will shortly be engaged in laying out a system of fire guards, to be cut out during the coming spring and summer. Nature has made it 
an easy matter to carry out the work, owing to the numerous lakelets within the reserves. These will be used, when practicable, in forming portions of the line. It is proposed, in constituting the lines which will form the fire guards, to make them from 50 to 100 feet in width, as conditions may require, and to plow up the outer edges to a sufficient width to make it safe to burn between them. If, in the following year, harrowing is not found sufficient to make an effective break, re-plowing will take place, and afterwards, at the most favorable time, the strip between the guards burnt off.

The danger, from fire, to these belts of timber, comes chiefly from the west and north-west. There are two causes which, as appears to me, explain this. The first is, that the prevailing winds in the fall of the year, when the prairie fires are most prevalent, come from a westerly direction. The second, that while settlement is generally found on the east, north and south sides of these belts of timber, thereby affording a means of check to the fire coming from that direction, there is practically little or no settlement on the west.

The rapidity with which this country is being denuded of timber should claim the attention of everyone interested in its general welfare and prosperity. Speaking from my own observation, I have little hesitation in saying that within the last fifteen years our timber resources have been diminished by one-half; whereas, with adequate protection from fire, the natural increment would have been far more than sufficient to have supplied demands, without any diminution whatever. Many settlers who, a few years ago, had wood conveniently near their farms have now to haul long distances, in many cases under trying conditions, to obtain their supplies, or else are dependent upon coal. Instead of their fuel costing them nothing, as in former years, they are now in the position of having to pay from $\$ 30$ to $\$ 50$ a year for this commodity. What this condition of affairs would mean if it became general, can easily be imagined.

Devastating fires occurred last year on Moose Mountain and on Turtle Mountain. A large number of men were em- 
ployed on both occasions, and every effort made to check the spread of the flames. Probably more timber was consumed by fire in these two reserves than would supply the settlement depending on them for twenty years. A bush fire, when once well started, cannot be extinguished by any present known means. Back-firing was tried without any apparent success, and the fires ran their course, regulated only by the wind, and died out when stopped by natural causes. Forest rangers will be placed in charge of these reserves the year round, and it is expected that with the aid of properly constructed fire guards and with the assistance of the municipal fire guardian service, the chances of fires getting into the timber on the reserve will be reduced to a minimum.

It is a regrettable, but an undoubted fact, that the settler, who is reaping the largest benefits from the preservation of the timber, and who has the most to lose by its destruction, is largely responsible for its diminution. The future is simply not taken into account by him. Economy in the cutting of his timber is not considered, and more timber is frequently left on the ground where felled than is taken away. Inexperienced men go into the woods for a set of house $\log \mathrm{s}$; upon being cut, a portion of the logs are found unsuited for the purpose intended, and are left lying in the woods; thus two trees are often sacrificed where only one is made use of. And the same thing may be said of the taking of timber for fuel ; only the best part of the tree being taken, the remainder being left in the woods to be a menace to the green timber in case of fire. I am glad to be in a position to inform you that this condition of affairs will be tolerated no longer. The government timber regulations now in force, provide that a settler cutting under permit shall take from every tree felled all the timber there is in it; and, further, that the tops of trees and other refuse made in the cutting shall be piled up in one place and not left, as heretofore, scattered through the bush. It shall be the duty of the forest ranger in charge of the reserve to see that these conditions are rigidly enforced. 
It should be the aim of the ranger to get rid of this lying timber as quickly as possible, and I think some special inducement should be held out to the settler to take this class of timber first, as it goes rapidly to decay. One way would be to make it free of dues and tax the standing timber. With the dead and fallen timber removed, the difficulty in controlling bush fires-especially in forests of deciduous trees-will be largely overcome. The lying timber can only be gathered, excepting with great difficulty, in the fall or early winter, before it becomes covered with snow. Very little of this class of timber has in the past been taken. The drawing of fuel supplies is left off until winter sets in, and then, the fallen timber being under the snow, the standing dry timber is taken, as being easier to obtain. Another source of great danger to the forests from fires is that large numbers of settlers go to the sloughs and lakelets in the woods for their hay, which is found in abundance in some places.

There are some settlers who, as a means of escaping the trouble and expense of clearing lands by hand, have resorted to the use of fire. The fire that occurred at Moose Mountain last summer, previously referred to, is said to have originated from the burning of one of these hay sloughs in the timber. Fires are also started by settlers clearing their lands of timber for cultivation. I have had many proofs of this. Hunters, fishermen and Indians are also responsible for starting many of the fires which have done so much damage to our forests. But a new and greater danger has arisen in the mining prospector. This individual considers it a duty he owes to his calling, to clear by fire all before him, to facilitate his search for minerals. The loss of the timber does not concern him. The effects of this are already only too apparent in our forests. It is estimated that the loss of timber to the Province of Ontario in the Lake of the Woods and Rainy Lake districts attributable to this source alone, is greater already than the value of all the minerals that will ever be taken out. 'The same thing is happening in British Columbia. This cause of destruction is one of the most difficult of 
all to deal with, as it is manifestly impossible, or almost so, to exercise any supervision over the mining prospector. The governing"authorities have come in for no little criticism for what is thought to be the lax manner in which the laws relating to prairie and bush fires are administered. But, while it is easy to criticize, it is not easy to suggest a more efficient means of preventing these fires. When it is considered what a sparsely settled and extensive country lies north of the 49th parallel and that inflammable material lies under your feet wherever you go, the difficulty of providing safeguards becomes apparent. The chief hope of a remedy, it seems to me, lies in an improved public sentiment on the question; and this, Mr. President, if I do not misunderstand the aims of your Society, is one of the objects you have in view.

Dr. Franklin B. Hough, who acted as Chief of the Forestry Branch of the Agricultural Department at Washington for several years, has gone into the subject of forest fires very exhaustively. In his report, Vol. 3, he devotes no less than 130 pages to that subject alone.

A circular was issued from the Department under his care, to its correspondents in the several States and Territories, with a view of ascertaining the extent of injuries that have been sustained and observed through forest fires, the causes of these flres so far as known, and the methods commonly employed for preventing them, or arresting them when started and under way. The circular invited such suggestions as might appear advisable concerning the means for preventing the continued recurrence of these calamities. Some of the suggestions and advice given are worthy of note and might be adopted with advantage. One correspondent sajs, in answer to the request for suggestions :-

"1. Open the eyes of the people to the danger, the immense destruction of property, the rapidly shrinking streams, the increase in the duration of droughts, the blighting of landscapes, and the general climatic effect. This can be done by national publications fitted for the common people, 
not by documentary reports. Force these upon the attention of all by tracts or placards in the places of common resort, in lumbering camps, in all centres of population adjacent to the forests."

"2. By stringent national and state laws, fastening responsibility upon careless guides and tourists, and also upon those who are clearing lands. When a man wishes to burn a fallow piece he should girdle it with swaths. Responsible men, who would not think of endangering their neighbour's house by a bon-fire in their garden, think nothing of letting loose their fallow fires into adjoining timber."

The correspondents who offer suggestions almost always ask for more vigorous laws, with rewards offered for the conviction of delinquents, while others admit the existence of laws, but deplore the fact that the laws are not enforced. A great change has taken place in regard to the enforcement of the Fire Prevention Act within recent years. There were more prosecutions for violations of this act in the last two seasons, probably than during all former years.

Much good work has been done by the North West Mounted Police Force in carrying into effect the fire ordinances of the North-West; and by their efforts immense loss to the timber has been averted. Under the Statutes of Manitoba the municipal councils are empowered to appoint a fire guardian service. Repeated efforts have been made to get these councils to take action in this direction, but with poor success. A few of the municipal councils have made such appointments and are showing an interest in all steps being taken to conserve the timber. The difficulty appears to be to get suitable persons to accept the office.

The burden of any work in connection with fighting fires, would rest as a matter of course, on those settlers living nearest the timber. and, while it is regrettable to have to make the statement, the reason given for these men for refusing to accept appointment is, that the settler living at a greater distance, and who benefits equally by the preserva- 
tion of the bush, gives no assistance in case of fire, and hence they do not feel called upon to do all the work.

The Society, I believe, is doing good work, along horticultural lines (if I may borrow a commercial expression) in the Province. Would it be practicable to make an effort on its own behalf, or through the Provincial Government to educate the people up to a proper appreciation of the value of our forests to the community, and to enlist the services of the many throughout the country who have the ability to place the subject before the people in its proper light. A study of the principles of forestry is, in my opinion, a great need in this country.

It is not yet too late, by attention to this subject, by putting into operation the general principles which underlie forest management, to recover much of the loss that has already taken place, and to ensure an adequate supply of timber for future generations in Manitoba and the Northwest Territories. Where fires occurred, in most cases a new growth is springing up, which will, under proper forest management, in a few years grow to be useful timber.

Keep down fires, and restrict cutting to the dry and fallen timber and mature trees, and there need be no alarm felt for the future in respect of timber supplies.

I regret, Mr. President, the inadequate manner in which I have been obliged to treat this important subject, but having only returned to my office this morning, after an absence of two months, I found it impossible to give the matter the attention it deserved, and to take up some other phases of the question, which impress me as equally important, such as the effect of forest on the water supply and climate. These might be brought up for discussion at a future meeting. 


\section{Bee Keeping.}

BY S. A. BEDFORD.

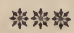

I wish to state at the start that this subject is not new to ine but giving an address on it is new to me. I am passionately fond of keeping bees. I suppose most of the visitors to the farm have noticed that I have always shown them the bees. I am not alone in this love for this insect. I find that the ladies of our household are also fond of it and we all find that it is very nice to have a supply of honey in the house as it takes the place of fruit to a large extent and you.all know that it is one of the best foods that we have.

'The pursuit of Bee keeping has much to recommend it, for instance :-

It affords healthful out-door exercise.

It enables us to utilize what would otherwise go to waste, and yields a delicious food for the table.

It opens up a wondrous world to a close observer, for the life history of the bee is a delightful study.

It adds to the wealth of the nation; the product of honey in the United States for 1887 was thirty million dollars. I have not seen an estimate of the product in Canada, but have no doubt it is proportionately as great.

Bees are an important agency in fertilizing flowers, and by this means increasing the wealth of the country.

Can bees be kept successfully in Manitoba, and what are the requirements for carrying on the pursuit with profit and pleasure?

From an experience of seven years with bees in this country I feel confident that they can be made profitable and that much pleasure can be obtained in the pursuit of beekeeping.

Our winters, though severe, are dry, and bees are very free of disease. Honey plants are numerous ; we found our 
bees feeding on sixty varieties of plants last summer, many of them wild prairie flowers very general all over the Province. It requires: 1st. A fondness for the pursuit. Any person who thinks bees require too much attention and are not worth the time expended, should not invest in them.

2nd. A suitable location. In this country, where our winds are often very persistent, shelter, either artificial or natural, should be provided; a tight board fence will do, but a clump of timber or a ravine is better, because honey flowers are more plentiful in such locations.

3rd. A knowledge of the business can only be gained by experience, assisted by one of the many good bee books, such as Cook's Manual, The A.B.C. of Bee Culture, etc.

4th. A certain amount of patience and perseverance and a willingness to use care in small matters.

\section{HOW TO START.}

Purchase only a few colonies at first,-two or three is sufficient, - a Clarke smoker, $5 \mathrm{lbs}$. comb foundation, four or five spare hives, besides a few minor articles, such as foundation wire, a good bee book ; study up the details of each operation before undertaking it and the work will become easier and more interesting each week.

The yield per colony will vary much, all the way from nil to 150 pounds, but perhaps 40 to $50 \mathrm{lbs}$., spring count, is about the average, although many report larger returns; we extracted $45 \mathrm{lbs}$. per colony on the experimental farm last season.

Comb honey is of course the most valuable, pound for pound, but I find it less labor to work for extracted honey, and with us the increased returns more than made up for the lower price per pound, and besides, when working for extracted honey, more room can be given and excessive swarming prevented.

Do not remove bees from the cellar until the willows bloom, generally the end of April; place the hives facing the 
east, three inches above the ground, on bricks ; this keeps the hives dry and at the same time allows the bees an opportunity to walk up to the entrance should they be blown aside when alighting with a load. Crowd the bees somewhat in the early part of the season to maintain the natural heat. This can be done by the use of division boards. Keep all the colonies strong, uniting for this purpose, if necessary. As the weather gets warmer and the brood hatches, give more room ; when bees are found working on the outside combs, put on a super. As soon as the honey flow starts in earnest, give plenty of room, either by extracting or adding additional stories to the hive to prevent excessive swarming. Handle only in the evening - this will largely prevent robbing.

\section{HOW TO WINTER.}

On the experimental farm we have tried many different ways of outside wintering, viz: With coverings of chaff, sawdust, snow and mixtures of all these, but have failed with all of them and now winter altogether in a cellar. We see that each hive has $30 \mathrm{lbs}$. of honey, and remove to the cellar as soon as we think winter has fairly set in ; place the hives in a fairly dry cellar with a temperature as near to 45 above zero as possible. The openings are protected from mice by a piece of coarse wire netting and.a piece of bagging under the cover ; the cellar is kept as dark and quiet as possible.

If the above plan is adopted bees will generally winter well.

I would like to say here that there is room for a great many beekeepers in this Province. If you once take up the study you will find it very profitable and it is a business in which all classes, to a large extent, can take part; those living in the city as well as those living in the country. No matter how small a garden plot you have there is always room for bees. There is no fear of being stung if you handle them carefully. There is one good thing about the bee, he will never sting without giving warning and if you are acquainted with the language of the bee you can always tell when they are cross. The bee will fly in a different manner when it is going to sting; it will dart and strike and not fly quietly along. 
Question. What kind of bees do you keep.

Mr. BEDFORD. We have the pure Italian. They have golden stripes across the back. The pure Italian is supposed to be the best bee. The distance that a bee will cover is remarkable. I have found our bees nine miles from home.

Question. How often do you extract the honey?

MR. BEDFORD. Honey extracting depends upon the season. You can suit yourself about that. I might say that the honey produced here is superior to that produced in Ontario. It is certainly better than that which is sent up here.

Question. How many times do you allow them to swarm?

MR. BEDFORD. That is a subject that we have taken up during the past year. Two years ago we were troubled with excessive swarming. This year I gave them abundance of room and we had no swarms. By forcing them to make comb honey they will swarm more readily.

Question. How late in the season would you allow them to take possession of a hive?

MR. BEDFORD. It depends upon the season. You can easily unite the hives by gradually approaching them to each other. If there is any trouble between the queens let them fight it out.

You very seldom have to feed them as the native flowers here extend their blooming far into the fall, but if you do the best plan is to give them candy made by adding a very little water to granulated sugar and allowing it to simmer on the stove until it becomes brittle when cold. This candy agrees very well with them and there is no danger of illness anong them.

Question. What is the cost of starting to keep bees?

MR. BEDFORD. That depends very largely on where you have to import them from. Ours cost $\$ 12.00$ a hive but I think they sell from $\$ 7.00$ to $\$ 10.00$ here. $\$ 30.00$ would start an amateur very well. There are one or two men at Portage 1a Prairie who have bees for sale. .

Question. How close would you have them to high trees?

Mr. BEDFORD. We do not like to keep them too much in the shade. We find that bees in this country nearly always light on low bushes as the wind is usually too high for them.

Question. Which direction would you have them face?

MR. BEDFORD. They want the early morning sun as they start out very early in quest of food but they must be protected from the hot sun of midday. 
Question. Do you allow the bees to make their own combs?

MR. BEDFORD. No, we supply the foundation as it takes four times as much work to produce one pound of comb as to produce the same quantity of honey.

REv. Mr. BurMan. I would like to ask Mr. Bedford if he has had any difficulty with the honey in the matter of granulating. The reason I ask is this. There is in the Province a colony of Swiss and they are great bee-keepers. I have brought with me a sample of honey from that colony which they say is superior to Swiss honey which is the best in Europe. The Swiss complain that it will not granulate. That is why our friends in the East mix honey with glycerine. I am sorry to say it is true and $I$ know it for this reason, that a person who deals in Eastern honey told me a little while ago that the dealers always ask what per centum of glycerine you would like put in the honey and they say that as a rule they put in about 18 per cent.

There is something singular about this honey remaining liquid a1ways and I would like the bee keepers here to examine it. The Swiss think that there must be some particular flower here that keeps it from granulating. I got it last March and therefore it will be two years old next summer. This that I have in this little glass has been exposed to the air since last March. The moisture has evaporated but it has not granulated. I wonder if the gentlemen here can tell us anything about that and whether any particular plant would keep it from granu1ating.

MR. BEDFORD. I have heard it said, but I do not know on what authority, that there are certain plants of the artemisia family in California that the honey produced fron will not granulate. Possibly this honey was gathered from Artemisia. You know that it is very plentiful here.

Mr. Burman. I have made a great many inquiries but these people do not know enough of the country to be able to tell anything that would throw light upon the matter. I scarcely think that that will cause it. The Artemisia is a bitter plant and it seems hardly likely that it could be that, as the flavor is not at all bitter. It seems remarkable that honey that has been exposed to the air for so long will not granulate and remains so soft. If we can find out what plant this is it will be worth thousands of dollars to the Province. I have been trying to find this out for the past year and I am now having an analysis made for that purpose.

Mr. BEDFORD. Honey certainly does not always partake of the particular qualities of any plant. 'The best honey that we have at Brandon is produced from the Gum weed, and the plant has a turpentine odor but the honey is quite free from unpleasantness. 
Mr. BURMan. I would like to ask another question. We have some poisonous flowers here. Would Mr. Bedford or another who understands this think this would be likely to affect the honey. I would think that the flowers of such plants as the poison ivy would be likely to do this.

MR. BEDFORD. I think not. Of course there are a great many plants that bees will not feed on and we can leave it to their instincts to choose their food.

Question. How many pounds do you get from your bees?

Mr. Duncan. About 30 pounds this year but I have got as much as 100 lbs. from a colony.

MR. BEDFORD. How far is your place from here?

Mr. Duncan. About fifty miles South.

Question. Where do you winter them? In the cellar? Have you tried them outside and if so how does it work?

Mr. Duncan. In coming here I did not intend to have anything to say from the fact that I do not speak in public. I have had bees for about fourteen years. The first time I got bees it was simply to try if they would live in this country, as I had heard from authorities that they would not live in Manitoba. I came across some parts where there were vast quantities of flowers and that made me certain that bees would do well here. I found out those who had bees in the Province and purchased a colony. The first year I had them I was not home to attend to them. In the fall as an experiment I put them in the scrub and covered them with dry leaves, then put boards around them and piled in between the boards and the hives with straw. Six years ago I purchased another hive with the intention of keeping bees and during all the time I have kept bees $I$ have not lost more than seven hives. I have had them in the cellar and in the house and they do well either place providing there is proper ventilation, especially if there is moisture. I kept them in the cellar until they became too numerous, and then I built a little house on purpose. I find this year that they are in good condition.

\section{Question. How did you build your house?}

Mr. Duncar. Well, about four feet in a bank. I put stone around the bottom and had it about seven feet high. I think bees can be kept profitably provided those keeping them know anything about them. As your bees increase your knowledge of them will also increase.

Mr. E. F. STEPHENSON. I may say for the information of any here who may have thought of trying bees, that I got a colony two years ago and the first year I took out 28 pounds of honey and I think there must have been, by the weight of the hive, 40 or 50 pounds left. I put 
them in the garret and the temperature was possibly from $30^{\circ}$ above zero to $30^{\circ}$ below. Last year I took 28 pounds again from the same box.

Question. What was the cost of your hive?

Mr. E. F. STEPHENSON. I think $\$ 10.00$.

Question. Did you feed them anything.

Mr. E. F. StepHenson. Nothing during the winter.

Prof. BAIRD. I see Mr. Gunn, a bee keeper, here and we would like to hear from him.

Mr. Gunn. Well, Mr. Chairman, if it is experience you want I can give you some. The first time $I$ had bees was eleven years ago. In this eleven years I liave had as much experience as the average man. I had about three times as much experience as honey, but we got honey too. From the one colouy that we started with, we went up to thirty and down to three or four. Last year was our most disastrous year. They gave very little honey and wintered badly. We kept them in a stone cellar. We put in eighteen colonies and took out seven. They increased during last summer to fourteen and from these fourteen I got nearly 100 pounds a hive. They are now in flne shape, experience becoming less and honey more. I think the cause of death of so many of the colonies on our hands was too much moisture. This winter I took a look at thein and found a great number of dead bees, so I put some quick lime in the cellar and I think that takes up the moisture. I looked in to the cellar the other day and they seem to be very vigorous. I have known our cellar to go below freezing point several times. As for summer treatment of them we let them take care of themselves. As to the experience, we began to realize that it was best to leave the bees alone. We have never taken any trouble about having them face eastward, in fact we have them nearly always facing the South. Ours, when they swarm do not look for the low trees but for the very highest oak trees on the farm. They seem to want to get up in the world. Now we trouble ourselves about nothing but extracted honey. As to the quality of the honey it seems to be generally known that the Manitoba article is superior to any other. I have found it so in selling honey and I have frequently met people from other places who say that it is first-class and much better than what they get at home.

Mr. BEDFORD. From the experience we had two years ago I was led to believe that the trouble with our bees was caused by the honey they had stored for winter and that they had got among other things the honey-dew so one year I gave them candy instead of honey and they never wintered better. Candy is also cheaper than honey and when you once understand how to feed it, it is very easy.

MR. GUNN. The season of 1896 was a bad season from beginning to end, and so we got discouraged about extracting honey. As a 
general rule we feed then on rock candy or syrup made from granulated sugar but that failed and so we left them with the store they had gathered. We were inclined to attribute the great mortality among the bees to the fact that they had been gathering honey-dew. They must have got something that was not good to winter on. Last fall we extracted nearly all the honey and fed them sugar.

Miss Hind. What is the average price of honey?

MR. BEDFORD. I think this last season I sold only 125 pounds and that was sold at $\$ 10.00$ per 100 pounds. The retail price is $12 \mathrm{r} / 2 \mathrm{c}$. to $15 \mathrm{c}$. $10 \mathrm{c}$. is the wholesale price at Brandon.

PROF. BAIRD. This brings our programme to a close. There are one or two matters in the way of business to take up yet. One is that I would like to give an apportunity to any who are present to become members of the Society. After this it will be known, not as the Manitoba Horticultural Society, but under some name which will not make any distinction between this province and the Territories. Its aim is to distribute a knowledge of horticulture in its various branches, flowers, fruit, vegetables and trees, and we hope that the people, not only of the city, but of the country about, will rally round us and help to make a successful Society with a considerable membership. No member whose name was placed upon the programme has failed us, and I know that some of them have done so at considerable inconvenience to themselves. Many in addition to those who were invited have spoken promptly and to the point.

A motion regarding the prohibition of nursery stock was put to the meeting and carried.

Mr. GREIG. I move that a vote of thanks be tendered to these gentlemen who have so well contributed to the success of our meeting by their papers and other information. I am sure that the papers and addresses have been very educative and instructive ; and to the Council for the use of the Council Chamber, and also to the railway companies for the reduced rates, and to Mr. Alston for the plants which have been loaned to decorate the room. Carried.

QUESTION. Might I ask what is the membership in the country?

PROF. BAIRD. There are fifty members, and perhaps half or a little more than half belong to the city, and the others are scattered over the Province and the Northwest Territories. We expect to advertise and take more aggressive measures to secure members in the country.

The meeting then adjourned. 


\title{
STRAWBERRIES,
}

\author{
BY H. C. WHELLAMS.
}

March 18th, 1898.

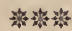

A. B. C. OF STRAWBERRY CULTURE.

As it is the aim and desire of this society to have as much practical information as possible, it will not be within my province to go any deeper into this subject than the experience of the last four years would indicate, and this only brings me to the A. B. C. of Strawberry Culture. I believe the time has now arrived when we may consider that the growing of Strawberries for market, in Manitoba, has got beyond the uncertainty of the experimental stage, and we can now say, without hesitation, that in this province we can grow as fine flavored and almost as large berries as are grown in Ontario. In making this statement, I am fully aware of the responsibility attached to it, but when I state that a number of gardeners, in the vicinity of Winnipeg, have had fair crops of first-class fruit for the last six years, I consider these facts warrant such an opinion.

Of all kinds of small fruits there is not one that will repay the expense and trouble of manuring as will the strawberry. It delights in a deep, well-enriched and thoroughly cultivated seed bed; it will do well on a variety of soils as long as there is good drainage. Preference may be given to sandy locations over heavy clay, as the former will be earlier and is much easier to work, which is a special advantage in the setting of young plants. The first essential to success is the establishment of good, strong vigorous plants ready for planting in previously prepared land during the early growing seasons of spring and summer, kecping in mind the earlier 
they are planted the better will be the crop the ensuing year. In other countries it is usual to plant both in the spring and fall ; but I find that plants set out in the fall in this country invariably fail to become well enough rooted to withstand the winter and give good crops the following season, and a plant that does not thrive from the first time that it is put into the ground will never amount to anything as a fruit producer.

For growing plants, it is best to select them from stock that has not been allowed to fruit, but which has been kept expressly for that purpose. It will be found that plants grown in this way will be more vigorous than those grown from stock that has been partially exhausted by fruiting. There are several methods of cultivating plants, of which I think the two following are the best: The first is to take small flower pots three inches in depth ; these are filled with specially prepared, moist, rich soil ; they are then completely embedded below the surface. The runners are placed over the pots and held in place with a small, flat stone, or with a small wooden peg. With a little moisture and favorable weather, the little rootlets will soon find their way into the fine earth waiting to receive them; and in a few weeks the plants will be ready for removal. Another and much simpler plan is to put in the little plants as they are thrown out on the runners of the older stock. A little care in setting the runners will be well repaid by a better stock of well-grown plants ; if left to catch where they can, high winds will often do a great deal of harm in shifting the runners, and so disturbing the young plants before they are well rooted, and in this and other ways it is often too late before they become well enough established to stand removal. No young stock should be allowed or expected to bear fruit the first season after planting, nor will it be found profitable to allow even the few flower trusses they throw out to remain; these should be pinched off, as the gain made in the small amount of fruit they will bear the first season, will not compensate for the drain it makes on the vigor of the plant. I fancy I hear someone say I can't afford to let any crop have the use of my 
land and not give me any return for the whole of one season, but though these plants occupy the ground for a whole season the intervening space need not be entirely wasted. It is both economical and essential for horse cultivation to allow from two and a half to three feet between the rows, as recourse can then be had to inter-cropping. For occupying this space between rows, onions are particularly useful ; the tops do not spread, while the bulbs are highly profitable. Two or three drills may be grown between the rows without injury to either crop.

\section{METHODS OF PLANTING.}

I believe there are more plants of all kinds lost from careless and improper methods of planting than from any known cause. In order that I may make myself more clearly under-

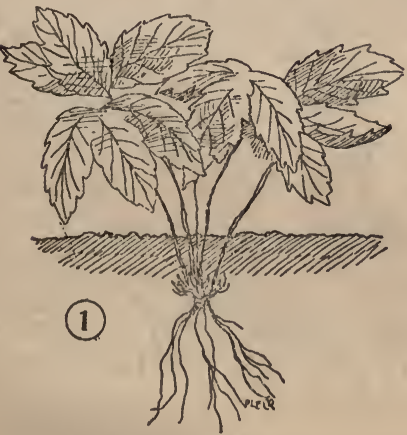
stood as to what is to be desired and what is to be avoided, I have prepared the attached illustrations. In the first figure you will see the plant has been buried too deeply, the heart is covered, and consequently cannot grow.

In the second it is not planted deep enough, and the roots are too straight in the ground.

In the third the hole has not been dug deep enough, the roots striking the hard surface, causing them to double up in an unnatural position, with the inevitable consequence, the death of the plant during the first spell of hot, dry weather.

The fourth plate represents the proper method of planting strawberries; the roots are spread out in natural position; they are able to gather as much nourishment from as far around the plant as it is possible for the roots to reach. They are all feeding in a different place. The heart of the plant is not buried; the fresh shoots coming through the crown meet with no resistance, having to push themselves through an inch or two of earth, and still the neck or collar 
of the plant is not exposed to the air to become hard and dry, with the resulting contraction of the sap vessels. One plant planted like this is worth a dozen of the others. The inexperienced I wish particularly to impress with this point; remember there are many ways of doing things wrong to every one way of doing them right, and a plant that is not properly planted in the first place will be nothing but a fruitful source of annoyance and disappointment to its cultivator.

In selecting a spot for a strawberry bed it is necessary to have it located in a somewhat sheltered position, in order that the snow will lie upon it until quite late in the spring. If you have not the desired shelter belt,

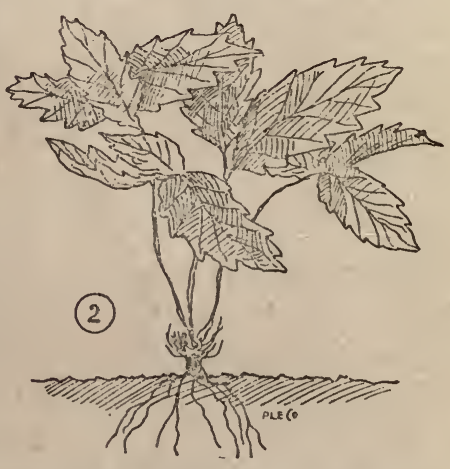
efficient and profitable protection can be had in the following manner : Plant rows of raspberries or other bush fruits, eight feet apart, filling in the spaces between with strawber-

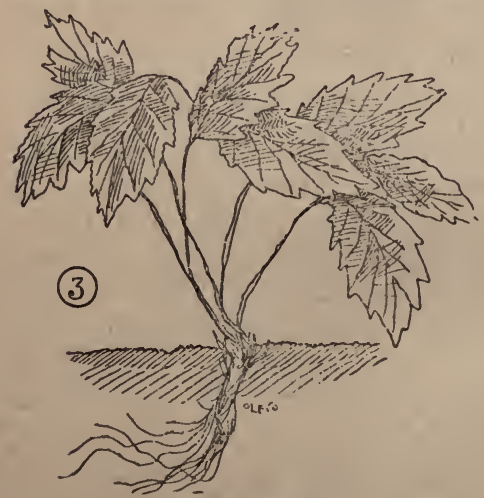
ries to within three feet of the canes or bushes; this will not only have the effect of holding the snow, but will give plenty of light and air to the latter fruits.

\section{GENERAL, MANAGEMENT.}

This consists in snipping off the runners as fast as they form, except when they are wanted for producing plants ; this method is somewhat new and I consider it a long way ahead of the matted system. It has been followed in England for about twenty years and is now extensively used in the United States. From the state of Michigan we have one grower remarking, that he would no more think of going back to the matted row system than 
think of cutting his hay with a scythe. As the plants throw out runners they are persistently cut off, a new fruit stem resulting from every runner that is so cut. The plants will form pointing crowns from four to six inches across, and the result is, the fruit is more easily and quickly picked ; there is no danger of trampling on unseen berries, the crop is fully as good and you have perfect control of both weeds and plants, and are able at any time to hoe close up to the plant, thus keeping the plantation clean at all seasons. I have seen many good patches absolutely wasted on account of the inability of the owner to get among them to cut out the weeds for fear of destroying the fruit, whereas, had this hill system been followed, a timely hoeing before fruiting time would have saved the crop.

After the fruit is picked all rubbish must be raked off

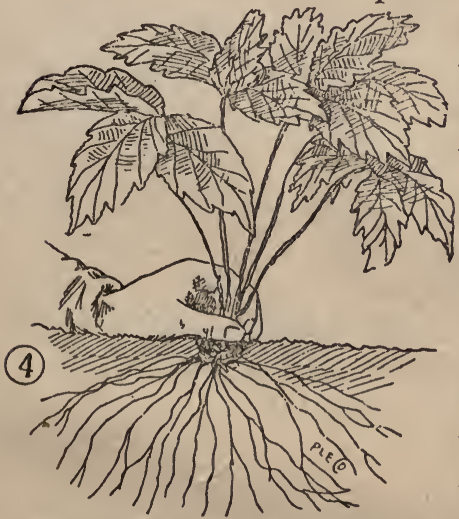
and burned, I say burned as it will then have no chance to harbor insects. The cultivator is run lightly between the rows. As soon as the ground is well frozen in the fall, it will now be in order to mulch the bed with a layer of straw manure, or preferably marsh hay, the latter to be preferred on account of the liabiality of there being so many foul seeds in the straw. This covering should be about three inches thick over the entire bed. In the spring care must be taken to go over the ground and clear away the mulch so that a hole is left above each plant, which will soon make its way above the covering. This layer of straw has a three-fold advantage. In the first place it keeps the frost longer in the ground, thus keeping back too early a growth in the spring, thereby lessening the chance of injury being done to the blossoms by spring frosts. It helps to keep down annual weeds and makes a nice clean cushion for the fruit to rest on; it also keeps the ground moist, and so prevents evaporation. 
GATHEIRING THE FRUIT.

In picking for market, the fruit should not be gathered while wet, as the moisture is injurious to its keeping qualities. Pick when the fruit is as dry as possible, and do not let it become too ripe. Always leave the shucks and a little piece of stalk on each berry. This will help them to retain their shape and ship better than if they are removed. Let the quality and size of the fruit be uniform throughout the box. Do not top off with a few large berries, and have all the small nobbled mess in the bottom. It is a dishonest way of doing business and a practice which will bring distrust and failure upon the follower of such methods. Let quality be your trade mark.

\section{VARIETIES.}

There are many different kinds, but there will be no disappointment if any of the following linds are selected: Sharpless, Captain Jack, Wilson and Crescent. The three first named varieties are perfect or bisexual. On the Crescent the blossoms are devoid of stamens and so-called pistellate or imperfect, and in order to produce fruit it is necessary to plant every other row with a staminate or perfect variety to pollenize the imperfect flowers. Some growers claim it is not necessary to plant more than a row every eight or nine feet for the purpose of fertilizing the pistellate varieties, but everything is to be lost by too few staminates; I think it is safer to be on the right side. There are numerous other kinds that are well adapted for this province, I know, but I have not yet had the opportunity of testing them on their merits. In conclusion, Mr. President, I wish to warn those would-be purchasers who have been and who are so often beguiled by the enticing plates of enormous strawberries which the salesman from some remote part of Ontario or the States shows them. My advice is to take no stock in such pictures, and do not listen to the promises painted in such roseate hues. Buy your plants from some reliable man who is in the business in Manitoba, who has acclimatized stock, and if you wish for some newer kinds get them from some reputable 
nurseryman whose climatic conditions are as nearly like our own as possible.

\section{DISCUSSION.}

PROF. BAIRD. This is a subject everybody either has had experience in or wants to have. There should be plenty of questions.

Mr. WHEI I AMS. I might say that I do not think there is a gentleman here who has had as much experience as Mr. Tomalin. He has grown strawberries for several years and has always had a successful crop.

Mr. Tomalin. If I begin I am afraid I will be pulling Mr. Whellams' paper all to pieces.

I find the best way with plants is to take them up about the last week in September. Take a bunch in your hand, trim them off with a knife and put them into the ground as close as possible and let them stand till Spring. You can then set them out and do not yeed to water them. Put them in two or three inches apart. Cut roots off short. Always cut them off about one-third.

Strawberry roots grow near the surface. Put them all in same depth. Make holes with dibber. I plant perhaps a hundred and not get one a quarter of an inch lower than another. I have'nt time to take pains with them and spread out the roots. The advantage of transplanting them up in the fall is that a number of sull white roots are formed. These hold a little ball of earth and support the plant till it is well established in its new position.

Mr. WhELLAMS. Two years ago we were setting out a bed of strawberries and some of my men went to work and set out six rows, 360 in a row. They planted them in the morning and made short work of it and said that it did not take half the time ny way did. I said I would finish them. Three weeks later every plant in my two rows was thriving, while more than a quarter of theirs had succumbed to to the heat because of improper planting.

Prepare ground first and see that it is moist enough. I have tried the old sytem and it killed most plants.

In the matter of the hill system. Land around here is infested with weeds and I find that after the first season plants run and become matted. With the hill system you are able to get in and pick weeds. In the matted row system you cannot do that. The plants cover the whole ground and if weeds come up you cannot get down on your hands and knees and pick them out. Last year a traveller who passed through here said he had been all over the province and mine were the finest lot of strawberries he had seen. 
W. G. ScorT. I have had a little experience. When I was planting I kept a cut before me all the time. I got through 500 in a day and I did not lose more than one per cent. I find that strawberries have too many enemies. I put up scarecrows to keep off birds and found in a few days that the wrens had built nests in hats and coat-slecves. The small boy is another enemy. I found it impossible to keep them off. It nuay be different in Kildonan and when I go into the strawberry business again I will move to Mr. Whellams' neighborhood.

I have tried the potting system. Put small pots in the ground so that the runners can take root in them and in the course of two weeks the pots are filled with roots and they usually bear the second year. I wot1d recommend this as the best way to manage in the city in a small way.

This system is used mostly for getting a crop the following year. You need a system entirely different from what they use in Ontario and the United States, the season is so short.

G. H. Greig. The hill system does not mean that the earth is raised about the roots of the plants, does it? The ground is all on the level, is it not?

Mr. Wheli,ams. Yes, all on the level.

Plant strawberries two and a half feet apart. As they throw out runners keep pinching off. The more runners you pinch off the larger the fruit grows. I always pinch them off with finger and thumb.

PROF. BAIRD. I have only some three or four hundred plants and have them in the hill system. Keeping runners pinched back is laborious business and I thought of getting a circular knife and using it to chop them down. I suppose any blacksmith could make it without much cost.

Mr. WHELLAMS. In some places some grow as much as 200 acres all planted in that system. A grower in the State of Michigan had something like sixty acres. He grows them entirely on that system. For us it is a particularly good one.

W. G. Scotr. How many crops should a strawberry patch be allowed to bear? Some authorities say two-others three.

W. H. Tomalin. The best crop I got off my land was two years ago. I had a bed and got two crops off it. It kept raining in the spring and $I$ was not able to make any other use of the bed. Mow near the rows. I am not afraid of cutting an occasional plant.

Question. How wide do you leave your matted rows.

W. H. 'Tomalin. I plant them four feet apart and let them meet. 
The worst trouble in growing strawberries is that they need so much water. It takes 27,000 gallous to put an inch of water on an acre surface.

I do not like the hill system. It is a great deal of work and trouble.

MR. WHEILAMS. If we are growing strawberries with the idea of never taking trouble we will not do much of anything. With hills I can keep weeds down ; it is impcssible to do that with the matted row system. I would advise people to try the hill system. Let them try a few plants and they will soon find out for themselves. As regards trouble of snipping off runners-if you have a large quantity of strawberries there are machines. Buy automatic runner-cutters.

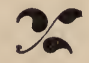

\section{The Dahlia,}

BY A. F. ANGUS.

絭竝

The Dahlia when well grown is one of the noblest and most beautiful flowers in cultivation. No garden flower has improved more in the last ten years by careful selection and cultivation (if you except probably the sweet pea), and no flower is so little known, in its perfection, in our northern country, or indeed in Canada. A bowl of well grown Dahlias, on a drawing room table with its wealth of gorgeous coloring and back ground of rich green is a sight to charm the senses of any lover of the beautiful. The old stiff, round, honeycombed flower of our grandmothers has been superseded by an endless variety in shapes and coloring, the most beautiful of these, resembling the chrysanthemum in form, far surpassing them in richness of color and delicacy of shading, from the finest flesh tints to the most brilliant scarlet. The perfect Dahlia, however, is not obtained without great pains, as to grow it well and to have it in perfection during our short summer, requires constant and industrious labor from April to September.

The Dahlia, as you are aware, is a tuberous-rooted plant, the root somewhat resembling a sweet potato. It can be 
propagated either by seed or by division of the root. The saeds should be treated like tender annuals, sown in the house in February or March and transplanted to two-inch pots and plunged into a hot bed in April or the beginning of May. The flowers, however, seldom amount to anything the first year, but the tubers will form during the summer, and if taken up in the autumu, carefully dried in a shady, well-ventilated place, and housed during the winter in a cool, dry cellar, they will be capable of producing fine flowers next year by merely placing them in the soil like potatoes after danger from frost is over. The roots may be divided into several parts, but great care must be taken to see that each part has an eye. These buds or eyes are not scattered all over the tuber as in a potato, but collected in a ring round the collar of the root. The eye, when the root is in a dry state, is scarcely preceptible, and nurserymen, to discover it, have often to place the tubers on a forcing bench or hot bed to start the eye, that is, to force the latent bud forward sufficiently to show where it is situated, before they can divide the plant to form new roots. Gardeners, as a rule, don't divide the roots, however, but they place the tubers in sand in a forcing bench with a strong bottom heat, early in February, and when the shoot is of sufficient size, they take cuttings which they also strike in sand. Small tubers are also grown to facilitate forwarding by mail, and these are obtained by growing the young plant in a very small pot and allowing the root to form, about the size and shape of a large walnut and then letting the plant dry off or wither. This is the best form of shipping Dahlias by mail, as these small tubers are a convenient size and just ready to spring when put in a pot. They can be brought from England or any distant land carefully packed, without any danger from frost early in the season, and can be brought well forward in the house in pots before time for transplanting to the garden. Care must be taken however, that you purchase these only from the most reliable dealers, or you may find many of them turn out to be blind or barren tubers, which will fill the pot with roots, but show no signs of growth above the earth. These blind tubers 
result from the carelessness of unscrupulous nurserymen being anxious to secure more rosts than his stock of cuttings will allow. Instead of making the base of his cutting the portion of the stem from which the branches shoot, he cuts his sprig half way between the branching parts. This will strike all right and produce a plant, but will invariably produce a blind tuber, which any amateur and most professionals would not recognize as such.

To obtain the best results and have the longest season of Dahlias, it is necessary to get, about the end of April or the beginning of May, wiry, small-stemmed plants, or the small tubers, I have just described, plant them firmly in four inch pots in specially prepared soil of one part loam or decayed sod, one part sand and one part well decayed manure; the remains of the former years hot beds, is the best, as the manure does not do to be too strong. Plunge the pots in an active hot bed, with sides rather higher then the ordinary frame to allow the plant to grow to a good size without pressing against the glass. The frame should be kept open during the day time as much as possible even on cold days when there is sunshine and no frost, and closed at night, having a covering of canvass or old carpet handy to protect it from our cold frosty nights, in April and May. When the four inch pots are filled with roots I find it best to change to six inch, keeping the plants in the frame till they are well developed, and even showing buds freely. They should be watered carefully every day in bright weather, and when the buds begin to show, given their first feeding of liquid manure, not too strongly at first. About the first or second week in June you may prepare for transplanting to your border. To grow Dahlias properly, they should have a border to themselves, on the south side of a wall or fence, protected also on the west by a hedge or by hardy shrubs, as the plants are very easily knocked about by our stong winds. The ordinary Manitoba soil is too heavy for the Dahlias, so if the location is not a sandy one, I would recommend placing prepared soil around the roots when planting out. I dig a hole for each plant about a foot or a foot and a half square, placing in this 
some soil the same that is used for potting, and pressing this firmly around the roots, and watering well. The plants having been well hardened by exposure during the day, and the soil, by this time, being sufficiently warm, there should be little or no check to the growth of the plant. The plants should be staked at once after being transplanted, using strong stakes about 3 to $3 \frac{1}{2}$ feet long, one or two stakes according to the size of the plant. They must be tied up at least once a week during the season of heaviest growth, otherwise they are liable to be broken by the wind. They must be watered over-head every day and given a feeding of strong liquid manure two or three times a week. Some authorities say that the entire border should be mulched with stable manure, four inches thick, but I have found that mulching the roots of each plant with some lawn scrapings does well enough.

The buds of the Dahlia grow in threes, like the Chrysanthemuin, a large one in the centre and small on either side, on each shoot. If you want well developed flowers it is well to nip off the two side buds, leaving the large centre one, and in the case of medium growers it is better to thin out a good many of the lateral shoots, but plants growing large flowers not so much so. The beauty of the flower is estimated principally by its perfectly circular shape without having any petals projecting beyond the others. Should any disk show in the centre of the flower, it is considered a great defect, and to allow this centre part to develop, prize growers often go to the trouble of placing a hood over the flower to keep the sun's rays from the rest of the flower that this disk may have time to grow.

Dahlias can be grown in three rows in a border, and can be ordered from the florist, as first, second or third row plants, the front being a dwarf variety and the third row reaching as high as four or five feet.

There are endless varieties of dahlias, Messrs. Cannell \& Son, a firm in England, famous for their dahlias, showing in their catalogue of 1897 more than 600 distinct varieties for 
sale. These are divided into different classes: The Show Variety, Fancies, Pompoms, Cactus, Singles and Doubles, Decorative and Reflex, etc., the latter being the most]useful for general garden decoration and should be generally cultivated, although I much prefer the Cactus shape. Of the latter, I have grown with success the following named varieties in order of merit:

Miss Violet Morgan, which is a beauty. The base of the florets being a fawn color, shaded towards the edge to a delicate tone of transparent pink.

Matchless, a rich deep velvety maroon of true Cactus shape.

Gloriosa, a deep red shaded scarlet, with large and finely formed flowers.

Mrs. A. Pearl, creamy white.

Robert Cannell, majenta, with bluish tint towards the top of the petals.

Of the Decorative and Reflex the best are Beauty of Wilts, a soft terra cotta.

Germania, white shaded and tinged with flesh.

Maid of Kent, intense cherry red, crimson ground, with pure white tips.

Constance, pure white.

Kaiserin, sulphur-yellow, outer florets tinged with yellow.

Of the Show varieties I have tried the following: John Hicking, the finest clear yellow, of grand form.

Julia Wyatt, a very large creamy white.

Agnes, also a fine yellow.

Wm. Jackson, a large rosy purple of the Fancy varieties.

Prince Henry is a beauty; lilac with right purple stripes, very large.

John Forbes, fawn color, stripped maroon.

Eric Fisher, buff, striped with scarlet.

Comedian, orange, ground flaked and speckled, crimson and tipped with white.

The largest Dahlia I have grown was La Colosse, a dull red of good shape, which measured twelve inches across the 
flower to the stem. This is the largest Dahlia grown, I believe, and strange to say it flowered very early, about the 4 th or 5th of July, too early for last year's show, and sad to relate died young, and I think from too rich feeding or too strong manure at the root.

This short paper has been prepared more for the purpose of starting a discussion on the subject from which we may have benefit, than for any practical information it may give, as a person with only two years' experience can hardly be called an authority on Dahlias.

\section{- DISCUSSION.}

Question. Do you advise keeping the roots in the cellar?

MR. ANGus. I have succeeded best when I kept them in the cellar without heat. They must be absolutely dry. Dry them in the garden in the sun or in a shed well ventilated.

PROF. BAIRD. My difficulty in the matter of growing Dahlias has been in the winter time when they do not grow at a11. The only place I have which is at all suitable is a cellar in which there is a furnace. I have no trouble with dampness, but it is too warm. Perhaps the mistake has been in putting them away in the autumn. Is it not advisable to look after them three or four times in the course of the winter and moisten them in the box in which they are packed?

Mr. Alston. I find it better not to pack them. Packing heats them and they are apt to be shrivelled up in the Spring. Take them out of the garden in the fall and put them in a bnx and keep them in a shed from fifty to sixty degrees and they will be all right-neither too dry nor too wet.

Mr. WhELIAMS. We put away about half a bushe1; took them up, shook off the earth and put them in the root house. About two months afterwards they were the consistency of thick porridge. The reason probably was that they were not dry enough. Temperature does not seem to make as much difference as the condition in which they are put away. Recently we manage better; we put them in a roothouse with a lot of potatoes. The conditions that are suitable for potatoes seem to suit the dahlias.

Mr. ANGus. A good deal depends upon whether they are ripe enough when they are taken up. If a potato is not thoroughly ripe it is not fit to keep. It is better to leave the dahlias in the ground from the time when they freeze down in September or the beginning of 
October, till the frost becomes severe enough to stiffen the surface of the soil, say early in November; this gives time for the tubers to mature.

Mr. Tomalin. What kinds of Dahlia are best for this country?

Mr. ANGus. All are pretty good. The dahlia grows very well in this country?

Mr. Tomalin. Do you grow yours from seed? I tried that plan last spring; a considerable number of the plants have formed small tubers but as yet some merely have roots.

Mr. ANGus. I have not tried growing plants from seed.

PROF. BAIRD. I have no doubt that to grow them to as great a degree of perfection as Mr. Angus has, requires a good deal of carestarting them early in the greenhouse and tranplanting them once or twice. But the average amateur can get good returns by just planting dry roots about the middle or 1atter part of April, or a little laterany time when it is suitable to plant potatoes. If young shoots come up before the frost is past they are liable to be cut off by frost. For two years part of mine have been planted in the ground without being in a hotbed at all and I have had good growth. They do not bloom as early as those started in a hotbed; still they have a long season of bloom before the frost comes and the flowers reach as great a degree of perfection as those that were forced in the earlier part of the season.

Finis. 


\section{NDEX.}

Affiliation of Societies.......................... 57, 59

Anemone ...................................... 43

Annuals ....................................... 40

Annual Report .................................... 50

Apple Growing ................................ 60

Barberry ...................................... 17

Bee Keeping ......................................... 95

Birds, Protection of .............................. 86

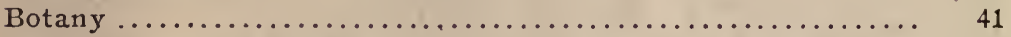

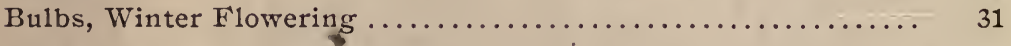

Change of Name of Society........................ 59

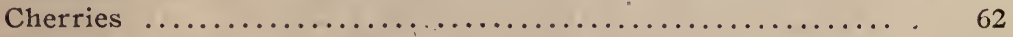

Climate, Its Influence on Trees....................... 23

Constitution of Society $\ldots \ldots \ldots \ldots \ldots \ldots \ldots \ldots \ldots \ldots \ldots \ldots \ldots, 5$

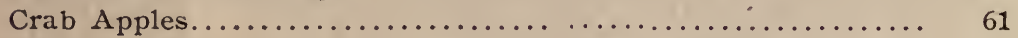

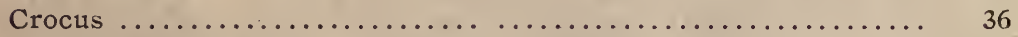

Currant, Flowering............................. 17

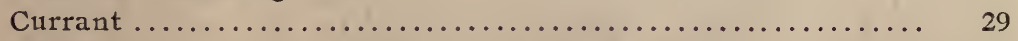

Cyclamen... ................................... 33

Dahlias .......................................... 111

Fall Planting $\ldots \ldots \ldots \ldots \ldots \ldots \ldots \ldots \ldots \ldots \ldots \ldots \ldots \ldots \ldots \ldots \ldots \ldots \ldots \ldots \ldots \ldots \ldots, 25$

Forestry ...................................... 88

Freesia........................................ 34

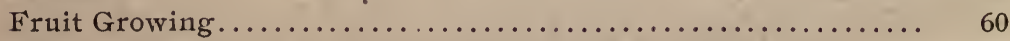

Fuchsia...................................... 38

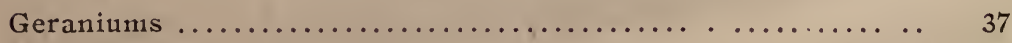

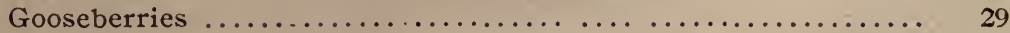

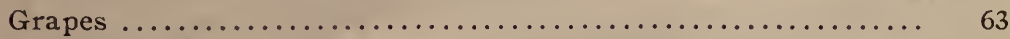

Guelder Rose .................................. 18

History of Horticultural Societies $\ldots \ldots \ldots \ldots \ldots \ldots \ldots \ldots, 35$

Honeysuckle................................ 17, 46

House Plants.................................. 9, 37

Hyacinths ......................................... 39

Hydrangea $\ldots \ldots \ldots \ldots \ldots \ldots \ldots \ldots \ldots \ldots \ldots \ldots \ldots \ldots \ldots \ldots \ldots \ldots \ldots \ldots \ldots \ldots \ldots \ldots \ldots, 77$

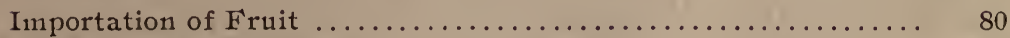

Insects on House Plants............................ 13

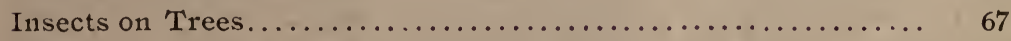

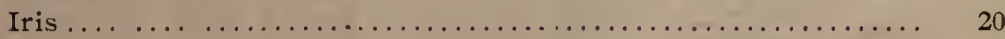




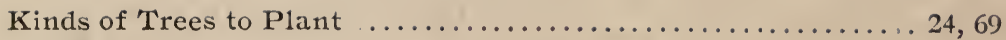

Lilacs . .................................... 16

Lilies ..................................... 35, 49

Members of Society ............................. 7

Minnesota, Horticulture in ........................ 55

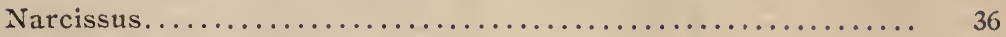

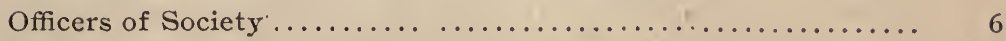

Orchid....................................... 49

Ornamental Shrubs............................. 71

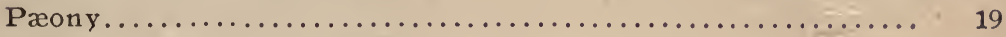

Palms.......................................... 38

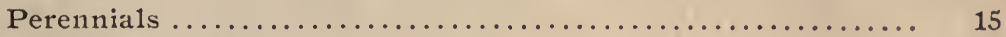

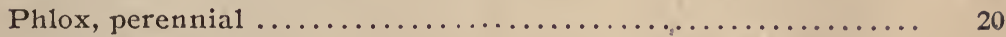

Planting Trees................................... 63

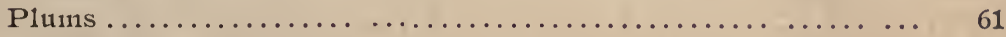

Potting House Plants ........................... 13

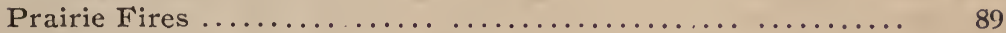

Prairie Flowers... ........................... 41

Protection of Birds ............................. 84

Protection of Plants in Winter .....................64, 66, 73

Raspberries.............................. 76, 78, 79

Report, Annual................................ 50

Repotting House Plants............................ 13

Rhubarb........................................ 83

Roses, Hybrid perpetual........................ 21, 76

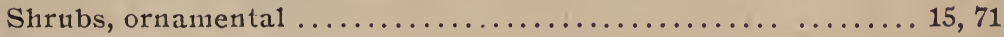

Sparaxis........................................... 36

Spirea (Snowba11).............................. 45

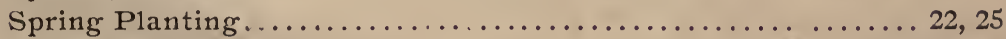

Strawberries.............................. 27, 83, 103

Transplanting House Plants $\ldots \ldots \ldots \ldots \ldots \ldots \ldots \ldots \ldots . \ldots \ldots, 13$

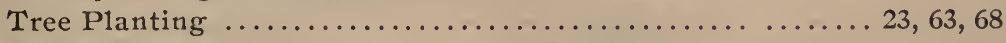

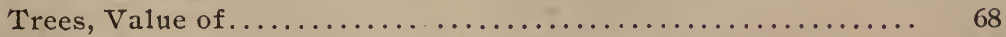

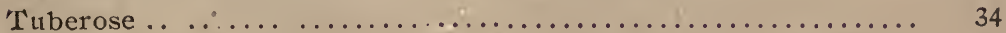

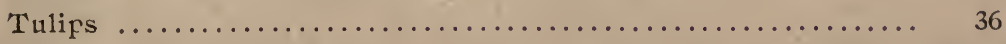

Varieties of Trees to Plant .......................... 69

Ventilation for House Plants....................... 10

Watering House Plants........................... 11

Wild Flowers.................................. 41

Windbreaks ....................................... 68

Winter Protection........................... 64, 66, 73 




(1.1)<smiles>C1=CCCCCC1</smiles>

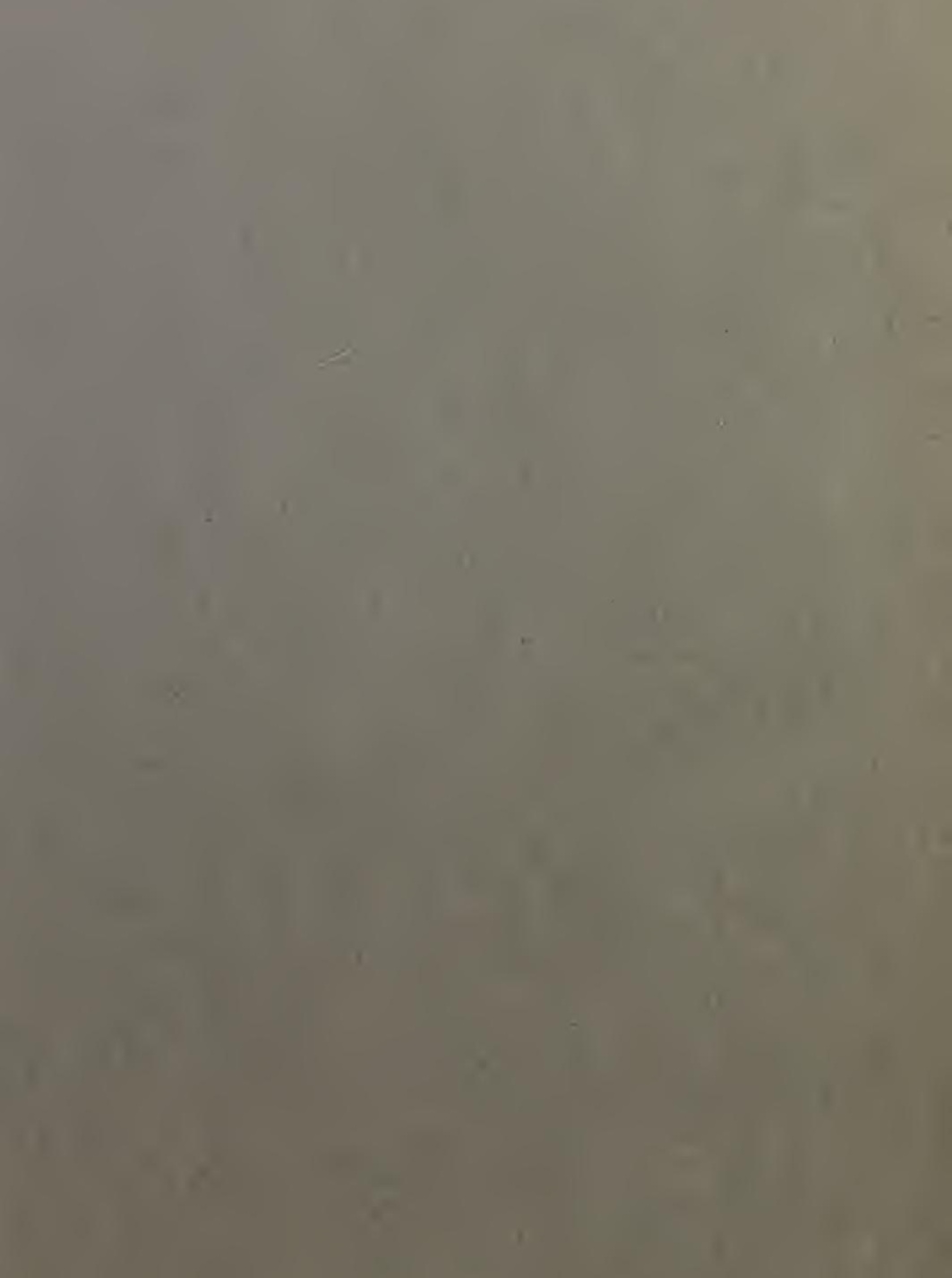




\section{YC 61561}


